NBER WORKING PAPER SERIES

\title{
THE EFFECT OF COURT-ORDERED HIRING QUOTAS ON THE COMPOSITION AND QUALITY OF POLICE
}

\author{
Justin McCrary \\ Working Paper 12368 \\ http://www.nber.org/papers/w12368 \\ NATIONAL BUREAU OF ECONOMIC RESEARCH \\ 1050 Massachusetts Avenue \\ Cambridge, MA 02138 \\ July 2006
}

For detailed comments on earlier drafts, I thank David Card, Ken Chay, John DiNardo, Guido Imbens, Jonathan Leonard, Heather Royer, and Emmanuel Saez. For comments that improved the paper, I thank Joe Altonji, Liz Cascio, David Lee, Nicole Maestas, Jesse Rothstein, Eric Verhoogen, Till von Wachter and seminar participants at UC Berkeley and NBER Labor Studies. I also thank Patrick Ronald Edwards, Clarice Bryce, Kevin Hudson, and Betty Turner of the Research and Technical Information Branch of the EEOC for their role in recovering much of the historical data used in this project. Adam Kingsley of the City of Chicago Department of Law provided data on the Chicago Police Department; Joanne Vanatta of the FBI Criminal Justice Information Services Division, data on the pre-1975 UCR; and Neldra Zeigler of the NYPD, data on entrance exam scores. For research assistance, I thank Stephanie Watt, Jeff Butler, Andrea Cann, Amy Hawkins, Katie Ikard, Alma Vega, and Shayesteh Zarrabi. Any errors are my own. The views expressed herein are those of the author(s) and do not necessarily reflect the views of the National Bureau of Economic Research.

(C2006 by Justin McCrary. All rights reserved. Short sections of text, not to exceed two paragraphs, may be quoted without explicit permission provided that full credit, including (C) notice, is given to the source. 
The Effect of Court-Ordered Hiring Quotas on the Composition and Quality of Police Justin McCrary

NBER Working Paper No. 12368

July 2006

JEL No. H4, H7, J1, J4, J7, K3, K4

\begin{abstract}
$\underline{\text { ABSTRACT }}$
Arguably the most aggressive affirmative action program ever implemented in the United States was a series of court-ordered racial hiring quotas imposed on municipal police departments. My best estimate of the effect of court-ordered affirmative action on workforce composition is a 14 percentage point gain in the fraction African American among newly hired officers. Evidence on police performance is mixed. Despite substantial black-white test score differences on police department entrance examinations, city crime rates appear unaffected by litigation. However, litigation lowers slightly both arrests per crime and the fraction black among serious arrestees.
\end{abstract}

\author{
Justin McCrary \\ University of Michigan \\ Ford School of Public Policy \& Dept of Economics \\ 440 Lorch Hall \\ 611 Tappan Street \\ Ann Arbor, MI 48109-1220 \\ and NBER \\ jmccrary@umich.edu
}




\section{Introduction}

Arguably the most aggressive affirmative action program ever implemented in the United States was a series of court-ordered racial hiring quotas imposed on municipal police departments. These quotas arose out of a wave of class action employment discrimination lawsuits filed in the federal district courts beginning in 1969. Court-ordered affirmative action in this sector has been both aggressive and persistent: Boston and Cambridge remain to this day subject to hiring quotas first imposed in 1973, and Philadelphia and Montgomery labored under similar affirmative action remedies into the 1990s. ${ }^{1}$ By the standards of current affirmative action proposals, these measures are remarkably interventionist. In this paper, I address two key issues. First, did these affirmative action policies succeed in raising the fraction of police officers who were African American, or did they merely ratify pre-existing trends? Second, what effect did court-ordered changes in hiring policies have on stated police department objectives, in particular crime reduction?

Evaluating the magnitude of these impacts is challenging. First, suitable data - in particular, historical information on black employment share and information on the pattern of litigation - are not publicly available. I use a new panel data set on 314 large American cities from 1960 to the present. To measure employment of African American police, I combine confidential information from the Equal Employment Opportunity Commission (EEOC) with published data from historical sources. To measure the onset of litigation against departments in this sample, I use published court decisions. Information on black employment share and litigation is combined with information on city demographics from the Census Bureau and on police staffing, arrests, and crimes from the Federal Bureau of Investigation.

The second evaluation challenge regards selection-litigated departments are not necessarily directly comparable with unlitigated departments. Both private litigants and the Department of Justice (DOJ) targeted those employers with the largest number of potential black jobs at stake - big departments with disparities between departmental black employment share and the city fraction African American. To circumvent this selection problem, I take advantage of the staggered timing of litigation against police departments and focus on event study estimates of litigation's impact, as

\footnotetext{
${ }^{1}$ Castro v. Beecher, 365 F. Supp. 655, 660-662 (D. Mass. 1973), and personal communication with Toni Wolfman; Freeman v. City of Philadelphia, 751 F. Supp. 509 (E.D. Penn. 1990); and U.S. v. City of Montgomery, 957 F. Supp. 1241 (M.D. Ala. 1997).
} 
in Jacobson, LaLonde and Sullivan (1993). Administrative delays in the processing of complaints by the EEOC, as well as capacity constraints facing the Employment Section of the Civil Rights Division of the DOJ in the early years of enforcement, led to substantial and plausibly exogenous variation in the timing of litigation against police departments. ${ }^{2}$

A third evaluation challenge is that unlitigated departments may have responded to the general phenomenon of litigation by increasing black employment share, confounding the direct effect of litigation with the effect of the threat of litigation. I address this question empirically by comparing the evolution of workplace demographics in unlitigated departments before and after the litigation of other departments in the same federal district.

The empirical analysis points to several important conclusions. First, despite substantial initial differences, by 1999 litigated and unlitigated cities employed black workers at similar rates, conditional on city demographics. Second, initial differences per se are not important enough to account for the gains accruing to litigated cities. Third, event study analyses indicate that the convergence in employment patterns between litigated and unlitigated departments occurred entirely in the years following litigation. My best estimate of the 25-year gain in black employment share is on the order of 10 percentage points. Using first-order Markov approximations outlined in Section III, I estimate that this corresponds to a 14 percentage point increase in the hiring fraction African American following litigation. Fourth, there is little evidence of litigation threat effects. Unlitigated departments in federal districts with litigated departments are no more likely to hire African Americans after litigation than they were before. Fifth and finally, there is mixed evidence of differences in police performance between litigated and unlitigated departments, but the bulk of the evidence suggests little to no effect. City crime rates, arrest rates, and the racial composition of arrestees all appear to be at best modestly related to litigation. Court-ordered affirmative action in municipal police departments may thus be an example of an affirmative action program with a substantial impact on workforce composition but a generally minor impact on productivity.

These findings relate primarily to two literatures. The first of these is concerned with the

\footnotetext{
${ }^{2}$ For example, in 1977 the National Association of Government Employees (NAGE) filed charges with the EEOC alleging discrimination by San Antonio against Mexican-Americans. The EEOC referred the case to the DOJ in 1980. DOJ acknowledged in 1989 that it had lost the paperwork for the case, and the trial did not proceed until 1989 (NAGE v. City Public Service Board of San Antonio, 40 F. 3d 698, 702). For introductory material on the variety of delays encountered by plaintiffs seeking to file an employment discrimination case, see for example Schlei and Grossman (1976), Rose (1989), and Landy (2005).
} 
impact of federal government labor market interventions on black economic progress (Freeman 1973, Ashenfelter and Heckman 1976, Brown 1984, Leonard 1990, Donohue and Heckman 1991). An important topic for this literature has been assessing the impact of the federal contractor program, which obliges firms which do business with the federal government to engage in affirmative action (e.g., Leonard 1984b). The literature's consensus is that the federal contractor program has had somewhat modest effects on black economic outcomes (Smith and Welch 1989, Leonard 1990). A few articles have sought to estimate the impact of court-ordered affirmative action on black economic outcomes (e.g., Beller 1978), but as noted by Donohue and Heckman (1991), no consensus has emerged on the evidence, and interpretation is difficult due to endogeneity problems. Wallace (1976) gives a detailed analysis of the impact of court-ordered affirmative action for AT\&T. Using industry-level data on class action employment discrimination litigation, black employment, and productivity, Leonard (1984a) estimates small productivity impacts of court-ordered affirmative action.

The second literature to which this paper contributes is the economics of crime, particularly the subliterature focused on police performance. The role of race in policing is a long-standing subject of general interest in the American urban context (Kephart 1957, National Advisory Commission on Civil Disorders 1968, Dulaney 1996). Recently, the topic has attracted the attention of economists (e.g., Knowles, Persico and Todd 2001, Antonovics and Knight 2004). Lott (2000) presents an analysis related to that here, focusing on the impact of affirmative action on city crime rates. Donohue and Levitt (2001) take a broader view and estimate the general impact of police department racial composition on the racial composition of arrestees using panel data.

The remainder of the paper is organized as follows. Section II describes the aspect of police hiring procedures which were the subject of litigation and discusses the legal rationale for judicial intervention into hiring practices. In Section III, a unique administrative data set is used to examine the racial composition of new hires for Chicago before and after litigation, and Markov approximations are used to convert estimated impacts on black employment share into impacts on black hiring share. Sections IV and V present evidence on the impact of litigation on black employment share and police performance, respectively, while Section VI concludes. Appendix I describes the data used, and Appendix II provides details on the Markov approximations used. 


\section{Background}

For much of the 20th century, municipal police departments have been required by state and local civil service regulations to hire in rank order by police department entrance examination. ${ }^{3}$ Although there are other aspects to police hiring, such as a criminal record check, it is generally agreed that the primary stumbling block to hiring is performance on the entrance examination. Thus, police department selection methods are essentially the employment equivalent of the Bowen and Bok (1998, pp. 31-42) model of race-neutral college admissions.

Many police department entrance exams, especially in the pre-litigation years, were aptitude tests akin to the verbal SAT. Detroit administered a three-hour I.Q. test (the "Otis") to applicants in the 1960s and into the 1970s. ${ }^{4}$ Over the same period, the District of Columbia used a civil service examination designed for positions in the federal bureaucracy. This test was comprised of 80 questions on vocabulary, reading comprehension, and analogies. These questions clearly measure aptitude, but are not related in any obvious way to police work. ${ }^{5}$ For example, two questions are:

[13.] The purpose of trademarks is to (A) show that a tax has been paid (B) distinguish the brand of goods manufactured $(\mathrm{C})$ show that a patent has been granted (D) indicate that goods are unadulterated $(\mathrm{E})$ distinguish home from foreign products

[14.] CRISP means most nearly (A) broken (B) frosty (C) brittle (D) burnt (E) dry.

The use of aptitude tests in police hiring is ongoing, largely because civil service service regulations require that some sort of test be used, and because departments and judges agree that quality police work requires some degree of aptitude. For example, the Memphis Police Department continues to use an I.Q. test to screen its applicants. ${ }^{6}$ Generally, police departments being litigated were not able to demonstrate statistically a relationship between performance on the job and entrance examination scores. In a particularly careful study of the New York City Police Department entrance examination, Cohen and Chaiken (1972, p. xiv) conclude that "the entrance examination

\footnotetext{
${ }^{3}$ Rank order hiring is mitigated to a certain extent by the so-called "Rule of Two" or the "Rule of Three", and by the requirement that those with sufficiently high scores pass additional hurdles, such as a background investigation or physical examination. Myrdal (1944, p. 539, fn. b) notes the prevalence of civil service systems in the North and South already by the 1940s, although he does not mention entrance examinations specifically. Greisinger, Slovak and Molkup (1979, p. 26) note that "[b]y the early 20th century civil service systems based on the merit principle were established in many state and local governments. Since then, they have grown in numbers at a very rapid pace, so that by the contemporary era they have become almost ubiquitous."

${ }^{4}$ Baker v. City of Detroit, 483 F. Supp. 930, 948-952 (E.D. Mich., 1979).

${ }^{5}$ Davis v. Washington, 512 F. 2d 956, 975 (D.C. Cir., 1975). The entire test is reproduced in the Appendix to the majority decision.

${ }^{6}$ Ashton v. City of Memphis, 49 F. Supp. 2d 1051, 1072 (W.D. Tenn., 1999).
} 
for patrolmen does not appear to predict any aspect of job performance measured in this study, other than the ability to pass later civil service examinations for promotion."

African American applicants, both historically as well as today, do not perform as well as white applicants on police department entrance examinations. ${ }^{7}$ For example, in the Detroit exams of 1967-1971, the African American pass rate was 44.3 percent, and the white pass rate was 80.7 percent.The Memphis tests administered 1981-1989 had a similar impact on black applicants. The pass rate for whites was a high 96.7 percent, but that for African Americans was 69.2 percent.

This disparity in black-white performance continued into "second-generation" police department entrance examinations that made clear attempts to improve the bearing of the questions on police work. For example, approximately 20-25 percent of the questions on the 1970 New York City Police Department (NYCPD) entrance examination asked applicants to supply the appropriate behavioral response to a hypothetical situation supposed to typify the day-to-day experiences of a police officer. ${ }^{8}$ Yet this exam excluded African Americans at almost the same rate as the Memphis exam: 81.9 percent of whites passed the 1970 exam, while 54.5 percent of African Americans did. ${ }^{9}$

Despite the best attempts of police departments to design tests that would satisfy the new legal regime in which they found themselves, the 1970s federal judiciary frequently found that use of these exams in police hiring was discriminatory, sometimes even after departments had spent many years attempting to devise a valid test. In reaching these findings, the courts relied on the notion of disparate impact, a legal theory developed by jurists in the mid- and late-1960s (Schlei and Grossman 1976). The central tenet of disparate impact theory is that an employment practice with no apparent racial motivation may nonetheless be interpreted as tentative evidence of discrimination if the employment practice disproportionately harms a group protected under civil rights law, such as African Americans or women. If a protected class group member may demonstrate that an employment practice leads to a disparate impact for his or her group, then the employer is obliged to demonstrate that the selection mechanism is predictive of job performance. The Supreme Court

\footnotetext{
${ }^{7}$ Compare with the general evidence on the black-white test score gap in Jencks and Phillips (1998). To my knowledge, Kephart (1957, p. 35) is the first to relate black under-representation on police forces to low average test scores. Speaking of Philadelphia, he notes "under-representation seems to stem not from discriminatory personnel practices, but from the failure of large numbers of Negroes to qualify on the civil service examinations."

${ }^{8}$ Guardian's Association of the New York City Police Department v. Civil Service Commission of the City of New York, 431 F. Supp. 526, 543 (S.D. New York, 1977).

${ }^{9}$ The Rand Corporation, in summarizing its study of the 1968 and 1970 NYCPD entrance examinations, concluded that it was "confident that the patterns observed for [the 1970 exam] are not unique to that exam but are most likely typical of the patterns for all recent civil service patrolmen?s exams." Quoted in 431 F. Supp. 526, 540.
} 
sanctioned this theory in 1971 in Griggs v. Duke Power Company: "The touchstone is business necessity. If an employment practice which operates to exclude Negroes cannot be shown to be related to job performance, the practice is prohibited." 10

Disparate impact theory was largely developed in cases against private sector defendants alleging violations of Title VII of the 1964 Civil Rights Act (CRA) and the equal protection clause of the Fourteenth Amendment. Although coverage of Title VII would not be extended to public employers until the 1972 amendments, disparate impact theory arguments were put to the courts between 1969 and 1971 alleging violations of the Fourteenth Amendment and the Reconstruction Civil Rights Acts of 1866 and 1871 (Reiss 1977). The courts were receptive to these arguments, and in many cases required police departments to hire according to quotas by race, foreshadowing the remedies that would result from Title VII litigation brought after 1972. That the Reconstruction Civil Rights Acts lay dormant for nearly a century before the courts began to enforce them underscores the idea that the federal judiciary may have played at least as important a role as Congress in the federal antidiscrimination effort. Historians studying the evolution of civil rights policy assign the courts a critical role, focusing on the courts' expansive interpretation of the 1964 CRA (e.g., Graham 1990).

Cases alleging discrimination in police departments could be brought either by private litigants or, after 1972, by the DOJ. DOJ involvement was important not only because of the high caliber of the government attorneys, but also because it placed in jeopardy the revenue sharing funds distributed to police departments by the federal government. ${ }^{11}$ Nonetheless, while the DOJ was undoubtedly an active player in the litigation, private litigants brought fully 80 percent of the class action suits studied here. A common pattern is for the local black police union to have brought suit on behalf of members and potential members. Unlike the education cases studied by Guryan (2004) and Reber (2003), the National Association for the Advancement of Colored People (NAACP) and other national civil rights organizations were essentially uninvolved in litigation against police departments. ${ }^{12}$

\footnotetext{
${ }^{10} 401$ U.S. 424,431 (1971).

${ }^{11}$ Crime Control Act of 1976, $\S 122(c)(2)(E), 90$ Stat. 2418 (1976). Based on my reading of police department cases, I believe this penalty, while used as a threat in conjunction with the Syracuse litigation, was only used against the Chicago Police Department.

${ }^{12}$ The NAACP participated in the Boston hiring litigation, the Pittsburgh hiring litigation, and in the Detroit promotion litigation; brought a series of suits against smaller departments: several muncipalities in New Jersey, including Harrison; East Haven, Connecticut; Corinth, Mississippi; and Evergreen, Alabama; and was the lead organization behind the Alabama state troopers case (NAACP v. Allen, 340 F. Supp. 703 (M.D. Ala., 1972)).
} 
Following a judicial determination that a police department entrance examination disparately impacted African Americans, there was typically a one to three year lag before any quota would be imposed. During this period, the judge would order the city to devise a test that either did not exhibit disparate impact or was job-related. If hiring was to proceed in the interim, temporary hiring quotas were sometimes put in place until the new exam was administered. If the department proved unable to devise a test that satisfied the court, the court often imposed an ongoing quota. ${ }^{13,14}$

\section{Litigation and the Integration of the Chicago Police Department}

Before turning to the main empirical analysis, I first consider the case of Chicago. The hiring and promotion practices of the Chicago Police Department (CPD) have been subject to litigation continuously from 1970 to 2000, and the remedies from this litigation include aggressive hiring quotas and the withholding of some $\$ 100$ million in revenue sharing funds. ${ }^{15}$ I demonstrate the impact of litigation on CPD hiring patterns using a unique administrative data set provided to me by the City of Chicago. The data set contains records on the race and hiring and termination dates of a large sample of police officers dating to the early 1960s. ${ }^{16}$ These data are superior to those collected by the EEOC, because they can be used to calculate the fraction African American among new hires for many years prior and subsequent to litigation. In contrast, EEOC data only contain information on the overall black employment share.

The CPD was first required to justify its employment practices to a federal district court judge in 1970, after the Afro-American Patrolmen's League initiated suit. At that time Chicago employed a substantial number of black officers, especially relative to other major cities. ${ }^{17}$ Figure 1 gives the black employment and black hiring share in the CPD from 1960 to 1997. The black employment share in the 1960s and early 1970s was roughly 18 percent. For comparison, 23 percent of Chicago

\footnotetext{
${ }^{13}$ Ongoing quotas either expired by their terms (e.g., a judge might require that 50 percent of new hires be African American until 40 percent of the force was African American) or remained in operation until judicially withdrawn.

${ }^{14}$ The departments under study lost approximately 80 percent of the cases brought against them in 1969 to 1980 , and interim or ongoing quotas were imposed in over 90 percent of the cases they lost in these same years. Cases brought in the 1980s and 1990s were less numerous, targeted small police departments, and were less likely to result in affirmative action requirements. Police departments litigated after 1980 won approximately 65 percent of the cases brought against them and only 43 percent of the cases departments lost resulted in a hiring quota. These figures are measured with a high degree of noise due to difficulties with unpublished decisions (see Appendix I), which motivates the paper's focus on the reduced form effect of litigation.

${ }^{15}$ See, for example, the discussion of the litigation in U.S. v. City of Chicago, 411 F. Supp. 218, 225-245 (N.D. Ill. 1976).

${ }^{16}$ See Appendix I for details.

${ }^{17}$ The CPD employed substantial numbers of black officers even as of 1940 (Raper 1940).
} 
residents in 1960 were African Americans, and 33 percent were African Americans in 1970. The DOJ joined the suit against the CPD in 1973, and in 1974 an interim hiring quota on behalf of African Americans was imposed, followed by an ongoing hiring quota in 1976. Figure 1 demonstrates that there was substantial compliance with the court's orders. In the years 1971-1973, the hiring share was roughly 10 percent. By 1975 it had climbed to 40 percent, and throughout the period 19751990, the hiring share averaged 32 percent. Although the demographic composition of new hires to the CPD responded dramatically to the hiring quota, the demographic composition of the police force changed only slowly, because of low quit rates. Using these data, I estimate an annual quit rate of 3.6 percent, which is within the range of the available estimates for other police departments in varying time periods. ${ }^{18}$ Considering the low police department quit rates, we should not expect court orders to lead to dramatic changes in black employment share. Instead, we would expect these to lead to a trend break in black employment share after the filing date of litigation.

For cities other than Chicago, high quality data on black hiring share are not available. However, I have collected data on black employment share for a large sample of police departments. If quit rates are stable over time, as they appear to be for police departments, it is possible to approximate the gain in the hiring share African American using data on the gain in the black employment share; I next describe a simple methodology for doing so. Appendix II develops the approximation

$$
F_{t} \approx \alpha F_{t-k}+(1-\alpha) \bar{f}
$$

where $F_{t}$ is the black employment share in period $t, \bar{f}$ is the average hiring fraction African American during the period $t-k$ to $t$, and $\alpha$ is a convex factor to be defined. The approximation is an identity if the quit rates for black and all officers are equal, and if hiring rates, the hiring fraction African American, and quit rates are constant over the period $t-k$ to $t$. Those conditions imply that $\alpha=\left(\frac{1-\bar{q}}{1+\bar{\varepsilon}}\right)^{k}$, where $\bar{q}$ denotes the quit rate, and $\bar{\varepsilon}$ denotes the year-over-year police force growth rate. ${ }^{19}$ Suppose the approximation is valid and contemplate a re-stated version of (1):

$$
\bar{f}-F_{t-k} \approx \frac{1}{1-\alpha}\left(F_{t}-F_{t-k}\right)
$$

\footnotetext{
${ }^{18}$ See Appendix II. Quit rates appear to vary somewhere between 3 and 5 percent.

${ }^{19}$ As discussed in Appendix II, the approximation remains accurate if quit rates and hiring rates are small and satisfy a law of large numbers and if black quit rates are approximately equal to overall quit rates.
} 
A simple way to think of (2) is as follows. Suppose that in period $t-k$ a police department is in a steady state, such that the hiring fraction African American is equal to the overall police department black employment share (i.e., $f_{t-k}=F_{t-k}$, where $f_{t-k}$ is the hiring fraction African American in period $t-k$ ). Litigation occurs, and an affirmative action program is imposed on the police department, resulting in an increase in the hiring share African American. After $k$ periods, the police department black employment share is observed to have increased by $F_{t}-F_{t-k}$. Then, with an estimate of the quit rate $\bar{q}$ and the year-over-year growth rate $\bar{\varepsilon}$, we compute $\alpha=\left(\frac{1-\bar{q}}{1+\bar{\varepsilon}}\right)^{k}$ and inflate the gain $F_{t}-F_{t-k}$ by the factor $\frac{1}{1-\alpha}$; the approximation in (2) justifies an interpretation of this quantity as the gain in the hiring share African American over the initial hiring share African American (i.e., $\bar{f}-f_{t-k}$ ).

To make these ideas concrete, consider Figure 1, where it is clear that the average hiring fraction African American from 1974 to 1997 far exceeded the historical hiring fraction African American. Using the 0.088 gain in the black employment share from 1974 to 1997, we can use the approximation in (2) to estimate the gain in the hiring fraction African American. Using a 3.6 percent quit rate and the observed annual growth rate of the police force of 0.06 percent, the estimated gain in the hiring fraction African American is $0.088 /\left(1-\left(\frac{1-0.036}{1+0.0006}\right)^{1997-1974}\right) \doteq 0.153$. Unlike the data analyzed in the main body of the paper, the administrative data from Chicago allow us to calculate the hiring share African American directly. Thus, we may assess the quality of the approximation by simply calculating the hiring share African American over the period 1974 to 1997 and comparing it to the prediction based on the approximation in (2). The actual gain in the hiring share African American in these data is 0.161 , which is roughly comparable to the prediction of 0.153 given above.

However, there is some discrepancy. The prediction based on the approximation in (2) will be understated (overstated) if the quit rate is overstated (understated). For example, a quit rate of 3.3 percent rationalizes the prediction and the actual, and a quit rate of 4 percent leads to a prediction of 0.144, which is too small. As shown in Appendix II, the prediction will also be understated if the black quit rate exceeds the overall quit rate. This is an important consideration. There is a large body of evidence indicating that in departments subject to federal court oversight on account of litigation, white officers harassed black officers with the apparent goal of inducing a high black 
quit rate. ${ }^{20}$ If the black quit rate exceeds the overall quit rate, then the true gain in the black hiring share is at least as large as implied by (2). On the other hand, it is possible that the black quit rate is less than the overall quit rate, given the clear incentives created by public sector wage schedules and the private sector black-white wage gap. ${ }^{21}$ On balance, the approximation probably yields predictions that are in the right ballpark, but care should be excercised in interpretation.

Did the federal court's aggressive intervention into CPD hiring practices affect police performance measures? Panel B of Figure 1 shows the size of the workforce (solid line, solid squares), the scope of crime in Chicago (solid line, open triangles), and two measures of arrests per crime (dotted lines). The figure shows that police per capita has remained nearly constant over the entire period. Crime per capita does appear to increase slightly in the same year as the quota imposition. However, it is also apparent that crime is a volatile series - the increase does not appear unusual, compared to other year-over-year changes in the series. Arrests per crime are mesaured by (i) the number of index crimes cleared, normalized by the number of crimes (solid squares), and (ii) the number of index crime arrests, normalized by the number of crimes (open triangles). The first of these measures is on the same data file as the number of crimes. The second of these measures is available in a greater number of years, but is taken from two separate data files and hence is presumably measured with more error than the first. The two series are both rather noisy, and it is not immediately clear whether there are any productivity effects.

Panel C of Figure 1 gives the fraction African American for arrests for all index crime arrests and for all arrests. The city fraction black is provided for comparison. These series are noisy as well and fail to reveal any clear pattern around either the litigation filing date or the date of quota imposition.

Perhaps the strongest conclusion implied by the police performance measures in panels B and $\mathrm{C}$ is that detecting productivity effects will require a statistically powerful approach, such as that pursued below. The focus on a large number of cities should help to eliminate much of the noise

\footnotetext{
${ }^{20}$ For example, "in a welcoming speech given to at least one academy class, a Captain reminded the cadets that while the Division of Police was forced to accept blacks and females, they did not have to keep them," Police Officers for Equal Rights v. City of Columbus, 644 F. Supp. 393, 401 (S.D. Ohio, 1985). For further examples, see for instance U.S. v. City of Buffalo, 457 F. Supp. 612, 632 (W.D. New York, 1978); Ways v. City of Lincoln, 871 F. 2d 750, 753 (8th Cir., 1989); Busby v. City of Orlando, 931 F. 2d 764, 781 (11th Cir., 1991); and Phillips v. Heydt, 197 F. Supp. 2d 207 (E.D. Pa., 2002).

${ }^{21}$ See Carrington, McCue and Pierce (1996) and Altonji and Blank (1999). An analogous context is blacks in the military, where in 1978 the black quit rate was lower than the overall quit rate; see Baker v. City of Detroit, 483 F. Supp. 930, fn. 58 (D.C. Mich., 1979).
} 
in the available performance measures through averaging, enabling us to detect the productivity effects of affirmative action.

\section{Litigation and the Composition of Police}

In this section of the paper, I first consider comparisons between litigated and unlitigated departments over time. Second, I consider estimators that take advantage of the timing of litigation. Third, I discuss threats to the internal validity of the estimates presented in the second sub-section. Finally, I present a direct test of litigation threat effects (cf., Rosen 1969), or the hypothesized tendency of unlitigated departments to integrate in order to avoid litigation.

\section{A. Contrasting the Litigated and the Unlitigated}

Litigated cities are far from a representative sample of the 314 cities under study. ${ }^{22}$ Table 1 presents means and standard deviations of key variables by litigation status for two samples: the "full sample" (all 314 cities) and the "long sample" (120 cities with information on black employment share dating to 1960). For cities in the full sample, estimates on black employment share are not necesarily available before 1969. All statistics in the table, and throughout the paper, are weighted by 1970 city population unless otherwise noted.

The table indicates that although only 30 percent of all cities are ever litigated, residents of litigated cities comprise nearly 58 percent of the 60 million residents in 1960, and 50 percent of the 75 million residents in 1999. While generally much of the federal antidiscrimination effort was focused on the South, that pattern is not true of the cases studied here. Among litigated cities, 23 percent of the population lives in the South, and 11 percent in the Deep South; among unlitigated cities, these statistics are 33 and 13 percent, respectively. Figure 2 is a map of the contiguous United States, with unlitigated cities represented as circles in the top panel and litigated cities represented as stars in the bottom panel. It is clear from the map that litigation was not confined to any particular region.

In substantive terms, the most important difference between litigated and unlitigated cities regards the city fraction African American. ${ }^{23}$ Throughout the sample period, 1960 to 1999, litigated

\footnotetext{
${ }^{22}$ See Appendix I for details on the selection of cities for study.

${ }^{23}$ Litigated departments are more likely to have experienced a riot. Of the cities analyzed here, 300 (90 litigated cities) were also analyzed by Spilerman (1970). I estimate that experiencing a riot in any of the years 1961 to
} 
cities had larger African American populations than did unlitigated cities. In 1960, 12 percent of the residents of unlitigated cities were African Americans, but 18 percent of the residents of litigated cities were. This six point difference grew to a ten point difference in 1970 and an eleven point difference in 1980 before stabilizing.

Police department black employment share did not initially keep up with these sharp gains. In 1970, litigated departments employed only 7 percent black officers. Between 1970 and 1980, black employment and population shares increased by equal amounts, and between 1980 and 1990, and again between 1990 and 1999, black employment share grew by more than the city fraction African American. Consequently, from 1970 to 1999, the difference between black employment and population shares, or the representation gap, in litigated departments converged from -0.17 to -0.09 . In contrast, the representation gap among unlitigated departments remained roughly constant at -0.10 in 1970 and 1980, and -0.09 in 1990 and 1999.

To economize on space, the estimates in Table 1 are given only at ten-year intervals. For all years for which estimates are available, Figure 3 gives the time series graph of the representation gap separately for litigated and unlitigated departments. The top panel gives estimates for the full sample, beginning with 1969. Several aspects of the graph are of note. First, unlitigated departments experience almost no convergence until around 1985. From 1985 to 1993 there is convergence of about 0.015, followed by a slight widening in the mid- to late-1990s. Second, starting sometime near 1977, litigated departments' representation gap converges to that of unlitigated departments. The convergence is very nearly linear in time starting around 1980.

Taking the numbers in Table 1 and Figure 3 at face value, a simple difference-in-differences estimate of the long-run impact of litigation on the representation gap is about 0.07 . This estimate could understate or overstate the impact of litigation. For example, the estimate may be too small if there are important threat effects to litigation, since then part of unlitigated departments' convergence in representation gap would reflect the effect of litigation. The estimate may also be too small if there is heterogeneity in the timing of litigation, since late-litigated departments do not have as many years as early-litigated departments to experience gains in black employment.

1968 increases the probability of litigation by roughly 40 percentage points (separate regressions for each year) and decreases the year of litigation by 3 years. Unlike the estimates on the impact of litigation below, these correlations reflect differences in city size; for example, controlling additionally for the log of city population leads to insignificant results for all but 2 of the 16 coefficients described. In these regressions, the 2 significant coefficients suggest that a riot in 1962 or 1965 delayed litigation by just over 4 years. 
These two considerations are addressed empirically in Sections IV.D and IV.B, respectively.

On the other hand, a difference-in-differences estimate may be too large. First, convergence in the representation gap may simply reflect pre-existing trends. Second, litigation may be associated with broader social trends which would have led to integration, even were litigation never to have occurred - the "social change" hypothesis of Donohue and Heckman (1991, p. 1605). I next discuss these two hypotheses in somewhat more detail.

Direct evidence regarding the pre-existing trends hypothesis may be obtained from the long sample of cities, for which information on black employment share predates 1969. Information on these departments is included in the final three columns of Table 1 . The estimates in Table 1 suggest that black employment share in 1960 was neither zero, nor yet as high as it would be in 1970. Interestingly, the 1960 to 1970 increase in black employment share is larger for unlitigated cities than for litigated cities, despite the fact that the black population share in unlitigated cities rose only marginally from 0.17 to 0.18 , while that in litigated cities rose from 0.19 to 0.26 .

The bottom panel of Figure 3 presents the time series plot of the representation gap for departments in the long sample. The figure speaks against a pre-existing trends hypothesis - the representation gap worsened substantially in litigated departments between 1960 and 1970. During the decade of litigation, 1970 to 1980, the representation gap slowed its negative slide. By the end of the decade the gap was closing. Unlitigated departments, in contrast, appear to have exhibited a slowly improving representation gap from 1960 to 1999, with some acceleration near 1985. In short, the figure is not consistent with an important role for pre-existing trends. Indeed, the evidence is consistent with the proposition that litigation reversed pre-existing trends, a proposition which is strengthened by the evidence from event study estimates shown below.

To be more specific regarding the type of mechanism underlying a social change hypothesis, suppose that the 1970s saw both a decade of class action lawsuits against municipal police departments and the beginning of a new, national hiring regime in which the fraction African American among new hires was only a little below the city fraction African American. ${ }^{24}$ In such a state of

\footnotetext{
${ }^{24}$ An alternative version of the social change hypothesis asserts that a case is more likely to be filed when there is general political pressure to integrate the police department. Two considerations suggest that this is not an important threat to validity. First, the estimates below are strengthened rather than weakened when unrestricted state-by-year controls are included. Since social change is likely to be similar for two cities in the same state, this pattern speaks against this specific version of a social change hypothesis. Second, the cases studied here only rarely involve civil rights groups (which would be expected to be heavily involved if litigation merely reflected a broader social movement).
} 
the world, it would mechanically be true that cities with low representation gaps would experience the greatest gains. This concern is addressed empirically in Section IV.C, below, using propensity score reweighting techniques (Rosenbaum and Rubin 1983).

The pre-litigation estimates in Table 1 and in Figure 3 suggest that litigation was targeted at big cities in which the police department black employment share did not initially rise as quickly as the city fraction African American. Economically, a pattern of targeted enforcement is notable for two reasons. First, it suggests that it may have been possible for a department to forestall a class action employment discrimination suit by hiring more black officers. This does not establish that threat effects contributed to the observed gains in black employment share in unlitigated cities. However, it does mean that such a story is not entirely implausible. Second, targeted enforcement is notable because previous research has failed to find evidence of targeting in the federal contractor program. Leonard (1985, p. 372) characterizes the compliance review program as a "random enforcement process", consistent with the earlier conclusions of Heckman and Wolpin (1976). ${ }^{25}$

\section{B. The Timing of Litigation}

Having considered comparisons between litigated and unlitigated departments, I now turn to an examination of the timing of litigation. This identification strategy is only feasible to the extent that different departments are litigated at different times. Figure 4, which gives the histogram of litigation filing dates of the cases under study, demonstrates that there is quite a bit of heterogeneity in terms of the timing of the cases brought against police departments.

Importantly, while the cross-sectional differences between litigated and unlitigated cities in confounders are often quite substantial, the differences among litigated cities litigated at different times are more minor. Table 2 gives weighted means and standard deviations of key variables for five different ranges of filing dates. Regional composition varies by the timing of litigation. However, key confounders such as city fraction African American are quite comparable across at least the first three filing date ranges. ${ }^{26}$

\footnotetext{
${ }^{25}$ In comparing the enforcement process of the CRA and the federal contractor program, it is economically interesting to note that judicial enforcement of the CRA is highly decentralized, with the decision to litigate largely in the hands of individuals who feel they have been discriminated against. When the CRA was initially passed, civil rights advocates took a dim view of decentralized enforcement, preferring an Equal Employment Opportunity Commission with cease-and-desist authority (Rose 1989, pp. 1133-1134).

${ }^{26}$ The fourth filing date range is also somewhat close to the others in terms of many characteristics, but the fifth filing date range is more similar to the unlitigated cities than to any of the litigated cities. However, in a weighted
} 
The estimates I present next correspond to least squares estimates of $\theta_{j}$ in the regression model

$$
Y_{i, t}=\mu_{i}+\lambda_{r(i), t}+\sum_{j=a}^{b} \theta_{j} D_{i, t}^{j}+e_{i, t}
$$

where $Y_{i, t}$ denotes the representation gap in department $i$ at time $t$ and $D_{i, t}^{j}$ are leads and lags of litigation filing dates, defined as

$$
D_{i, t}^{j}= \begin{cases}D_{i} \mathbf{1}\left(t \leq \tau_{i}+a\right) & \text { for } j=a \\ D_{i} \mathbf{1}\left(t=\tau_{i}+j\right) & \text { for } a<j<b \\ D_{i} \mathbf{1}\left(t \geq \tau_{i}+b\right) & \text { for } j=b\end{cases}
$$

where $D_{i}$ is an indicator for whether the department was ever the defendant to a class action employment discrimination lawsuit alleging discrimination against African Americans in hiring, $\tau_{i}$ gives the filing date for litigated departments, and $\mathbf{1}(A)$ is one if $A$ is true but is otherwise zero. ${ }^{27}$ Because not all parameters are identified as written, normalize $\theta_{0}=0$. The sequence $\theta_{j}$ then admits the interpretation of the representation gap difference from filing date to $j$ periods thereafter. ${ }^{28}$ I refer to the parameter sequence $\mu_{i}$ as "city effects" and to $\lambda_{r(i), t}$ as "region-by-year effects." The empirical work uses "regions" of the four Census regions, the nine Census divisions, and U.S. States, and also considers the restriction that the region-by-year effects are cross-sectionally constant $\left(\lambda_{r(i), t}=\lambda_{t}\right)$. Both the city effects and the region-by-year effects are nuisance parameters and are to be estimated by fixed effects.

It is important to note that, moving from left to right in the event study graph, the sample of cities driving the identification of $\theta_{j}$ is generally subject to change. For example, only earlylitigated cities can drive the estimated impacts of 20 years after litigation, since late-litigated cities will not yet have been observed 20 years after they were litigated. For this reason, I assign more weight to pre-litigation estimates obtained from the long sample - for many cities, the first period

\footnotetext{
regression, the contrasts will be focused between the first four filing date ranges because of their much greater size.

${ }^{27}$ This specification is similar in spirit to that used by Jacobson et al. (1993). For departments not having judicial interventions, the filing dates are irrelevant so define them to be zero. It is understood that $a<0$.

${ }^{28}$ This is a different normalization than that employed by Jacobson et al. (1993). Because their outcome variable (earnings) was available far before the first treatment date, the omitted category was earnings from long before the treatment. This strategy is not feasible here; the first treatment date (1969) is also the first year for which data on African American employment share in police departments is available for the full sample.
} 
of information on black employment share is 1969, which coincides with the onset of litigation.

These composition bias effects may be compounded by irregular observation of the outcome variable, coupled with heterogeneous treatment effects. An example will serve to illustrate. Because data on police department black employment share are available only at periodic intervals ${ }^{29}$ a city such as Oakland, California, which is litigated in 1969 is observed at litigation lags 0, 4, 5, 6, 8, and so on. A city such as Chicago, Illinois, which is litigated in 1970, is instead observed at litigation lags $-1,3,4,5,7$, and so on. ${ }^{30}$ In other words, in the absence of a corrective procedure, litigation effects will be estimated over partially-non-overlapping subsamples. Continuing the example, if Chicago and Oakland exhibit different gains in representation gap following litigation, then the event study graph will oscillate about the average effect of the two.

A natural method to correct for the composition bias is to linearly interpolate between observation years, taking care to correct the standard errors for both the induced serial correlation and degrees of freedom. This procedure seems particularly plausible in the present context, because of the low quit rate of police officers (see Equation (1)). Practically, the procedure amounts to using clustered standard errors at the level of city, inflated manually by a degrees of freedom correction to reflect that many observations are imputed.

The top panel of Figure 5 gives estimates of four specifications of Equation (3) based on the full sample. The thick solid line gives estimates from a year effects specification, the thin dashed line gives estimates from a region-by-year effects specification, the thick line with circles gives estimates from a division-by-year specification, and the dashed line with triangles gives estimates from a state-by-year specification. Although the four specifications give estimates that are rather different in their magnitude, the direction of the estimated effects is quite similar. In the first decade after litigation, black employment share begins to converge towards the city fraction African American. In the second and third decades the improvement becomes marked.

The convex shape of the event study graph is expected for two reasons. First, a cursory reading of the decisions in these cases indicates that judges were more inclined to aggressively intervene into police department hiring practices in the early years of the litigation. Litigation effects at the longest

\footnotetext{
${ }^{29}$ For example, black employment share for cities in the full sample is observed only in 1969, 1973, 1974, 1975, 1977,1980 , and so on.

${ }^{30}$ The litigation lags listed assume use only of the full sample data set. Estimates for the 1960s are also available for both Oakland and Chicago, as both are in the long sample.
} 
lags reflect primarily the experience of the earliest litigated. Second, there is heterogeneity in how long after the filing date the judge would wait before imposing an affirmative action remedy. Some departments would almost immediately be required to hire according to a quota regime, whereas other departments would be given some time to devise a new test.

The pre-litigation estimates for the full sample are based on less reliable information than those for the long sample. Estimates for the long sample are given in the bottom panel of Figure 5. The estimates for the long sample strongly suggest that litigation was not preceded by representation gap convergence. In the decade prior to litigation, the representation gap appears to have been constant or perhaps even growing. The post litigation estimates are not identical to those of the top panel, but are similar in magnitude. An important difference between the estimates in the top and bottom panels is that the four specifications in the long sample give estimates that are more widely varying than are those in the full sample. For example, while the region-by-year effects models are similar in the long and full samples, the state-by-year effects models are much larger in the long sample. Conversely, the year effects models are much smaller in the long sample than in the full.

Because of the near linearity of the estimate sequences graphed in Figure 5, it is natural to pool the individual estimates to estimate the post-litigation and pre-litigation slopes. The top panel of Table 3 presents a variety of estimates of the post-litigation slope for the full sample. Following the pattern of the specifications in Figure 5, Model 1 includes year effects only, Model 2 region-by-year effects, Model 3 division-by-year effects, and Model 4 state-by-year effects. The first four columns are the estimates for all 314 cities in the full sample. For these cities, the estimated slope is in the range 0.07 to 0.12 , with a standard error of about $0.02 .{ }^{31}$

Columns (5) to (8) exclude all unlitigated cities from the estimation. The litigation effects for these models, then, are based purely off of the timing of the litigation among the litigated. This

\footnotetext{
${ }^{31}$ As noted above, the reported standard errors here and throughout the paper are "clustered" at the level of the city and inflated by a degrees of freedom correction. More specifically they are the square root of the diagonals of the matrix $\left(n T / \sum_{i=1}^{n} T_{i}\right)\left(\sum_{i=1}^{n} X_{i}^{\prime} X_{i} w_{i}\right)^{-1}\left(\sum_{i=1}^{n} X_{i}^{\prime} \hat{e}_{i} \hat{e}_{i}^{\prime} X_{i} w_{i}\right)\left(\sum_{i=1}^{n} X_{i}^{\prime} X_{i} w_{i}\right)^{-1}$ where $T$ is the number of possible time-series observations, $T_{i}$ is the number of time-series observations for city $i$ with (unimputed) information on black employment share, $w_{i}$ is 1970 city population, normalized to sum to $1, X_{i}$ is the $T \times K$ matrix of time-series observations for city $i$, and $\hat{e}_{i}$ is the $T$-vector of fitted residuals for city $i$. Because there are a moderate to large number of cities in all specifications in Table 3, conventional t-ratio tests using these standard errors will exhibit approximately correct size regardless of the form of the heteroskedasticity and serial correlation within each city, provided that the residuals across cities are independent. (The only potential exception to this is the estimates in columns (21) to (24), which are based on only the 43 litigated cities in the long sample. For these estimates, t-ratio tests of nominal 5 percent size likely have actual size of 10 percent.)
} 
has some appeal: one might view with some caution estimates that rely on using the unlitigated as a model of the counterfactual evolution of the representation gap among the litigated, had they in fact never been litigated. Nevertheless, caution is warranted in interpreting these estimates. Identification leans on $a$ and $b$, the endpoints of the event study graph, which are usually thought of as nuisance parameters. To see the role played by $a$ and $b$ in identification, suppose that we were to estimate the pre- and post-litigation slopes in one step, by regressing $Y_{i, t}$ on city effects, year effects, and on the pre- and post-litigation trends $W_{i, t}^{1}=\left(t-\tau_{i}\right) D_{i} \mathbf{1}\left(a<t \leq \tau_{i}\right)+a D_{i} \mathbf{1}(t \leq a)$ and $W_{i, t}^{2}=\left(t-\tau_{i}\right) D_{i} \mathbf{1}\left(\tau_{i}<t \leq b\right)+b D_{i} \mathbf{1}(t>b)$. As $a \rightarrow-\infty$ and $b \rightarrow \infty, W_{i, t}^{1}+W_{i, t}^{2} \rightarrow\left(t-\tau_{i}\right) D_{i}$, which is linearly dependent on city and year effects in a sample with $D_{i}=1$ for each city. That is, the model is unidentified. Alternatively, a researcher thinking not of the event study graph but rather of a trend-break model might have defined the regressors as $\widetilde{W}_{i, t}^{1}=\left(t-\tau_{i}\right) D_{i} \mathbf{1}\left(t<\tau_{i}\right)$ and $\widetilde{W}_{i, t}^{2}=\left(t-\tau_{i}\right) D_{i} \mathbf{1}\left(t>\tau_{i}\right)$. This model is similarly unidentified: $\widetilde{W}_{i, t}^{1}+\widetilde{W}_{i, t}^{2}=\left(t-\tau_{i}\right) D_{i}$.

With these caveats in mind, it is interesting to note that the estimates for the 92 litigated cities are somewhat larger than the estimates that include all 314 cities. Estimates using all 314 cities can only differ from those using the 92 litigated cities due to different estimated year effects (or region-by-year effects, etc.). It is apparent that the year effects implicit in the estimates for the 92 litigated cities exhibit somewhat less of an upward trend than do the year effects from estimates for all 314 cities.

A pattern common to the estimates from both the full and the long samples is that the richer the set of geographical controls, the larger the estimated effects. For example, the state-by-year effects specification (Model 4) suggests that the impact of litigation is at least twice that suggested by the year effects specification (Model 1). This pattern is particularly pronounced for the long sample estimates in the bottom panel. This pattern strengthens the plausibility of the hypothesis that litigation is playing a causal role in black employment share gains; if litigation merely reflected omitted factors which were correlated with black employment share gains, then we would expect inclusion of richer geographic controls to make the effects smaller rather than larger. ${ }^{32}$

The bottom panel of Table 3 reports post-litigation trend estimates for subsets of cities in the long sample. These are generally similar to those in the top panel. The estimated impact of

\footnotetext{
${ }^{32}$ Comparisons across these specifications could in principle be invalid, since the observations identifying Model 4 are a subset of the observations identifying Models 1, 2, and 3. However, the estimates in columns (9) through (12) indicate that the effects are similar when the estimates are estimated over the same subsamples.
} 
litigation is altered only slightly when we restrict our attention to litigated cities and when we restrict our attention to cities contributing to identification of Model 4.

Because of the greater confidence in the pre-litigation estimates for the long sample, the bottom panel also presents estimates of the post-litigation trend less the pre-litigation trend. In all but one case (column (21)), these trend-break estimates are larger than the simple post-litigation trend, reflecting the negative estimated pre-litigation trends for cities in the long sample. ${ }^{33}$

\section{Social Change}

In Section IV.A, above, I discussed the possibility that initial differences in the representation gap could contribute mechanically to gains in black employment share. To address this possibility, I assign weights to the unlitigated, where the weights are chosen so that the reweighted distribution of the 1969 representation gap for the unlitigated is similar to the distribution for the litigated. ${ }^{34}$ The weighting function that achieves this balance is the ratio of the conditional to the unconditional probability of litigation. Such reweighting schemes are commonly used to generate counterfactual distributions (DiNardo, Fortin and Lemieux 1996) and in the program evaluation literature (e.g., Heckman, Ichimura, Smith and Todd 1998). ${ }^{35}$

Columns (13) to (16) of Table 3 give reweighted estimates of the post-litigation slope for the four specifications considered above. To estimate the conditional probability of litigation, I use a probit model with a third-degree polynomial in the 1969 representation gap; for the unconditional probability I use the sample average.

The estimates from this reweighting scheme suggest that the 25-year gain in black employment

\footnotetext{
${ }^{33}$ It is unclear whether the post-litigation trend is more or less appropriate than the trend-break model. For example, the post-litigation trend would be more appropriate if the negative pre-litigation trend would have abated soon after the filing date of litigation. However, the post-litigation trend would be too conservative, and the trendbreak model would be more appropriate, if the negative pre-litigation trend would have continued in the absence of litigation.

${ }^{34}$ One could also reweight the data to mimic the initial distribution of the representation gap for the unlitigated or for the average department. In this paper, I focus on addressing the counterfactual evolution of the representation gap in litigated cities, had they never been litigated. From a policy perspective, this is the right treatment effect to be estimated, since future affirmative action policies of this type would target departments with representation gaps similar to those of the litigated.

${ }^{35}$ The literature's motivation for reweighting is typically implicit rather than explicit. Short proof that reweighting balances potential confounders in distribution: let $X$ denote covariates to be balanced, $D$ an indicator, $g(\cdot)$ an arbitrary bounded, continuous function, and assume $p \equiv E[D \mid X] \in(0,1)$ and $\pi \equiv E[D] \in(0,1)$. Note that $E\left[g(X)(1-D) \frac{p}{1-p}\right]=E[g(X) p]$ and $E[g(X) D]=E[g(X) p]$, implying $E[g(X) \mid D=1]=E[g(X) w \mid D=0]$, where $w \equiv \frac{p}{1-p} / \frac{\pi}{1-\pi}$. The implication follows from the converse to the Helly-Bray theorem (Davidson 1994, Theorem 22.8).
} 
share may be slightly smaller than previously estimated. For example, the difference between Model 2 in column (2) (usual weights) and Model 2 in column (14) (reweighting the unlitigated to achieve balance) is about 0.023 ; that between the estimates for Model 4 is about 0.008 . A similar reweighting exercise is performed in columns (29) to (32) for the long sample. These estimates suggest that the degree of overstatement in the original estimates is between 0.003 and 0.012 . Unreported event study estimates of the impact of litigation on representation gap, weighting by the same factor, are visually quite similar to those presented in Figure 5.

\section{Threat Effects}

Testing a litigation threat effects hypothesis requires that we specify how beliefs regarding threats are formed. A natural approach in this application is to consider whether unlitigated cities respond to the litigation of other cities in the same federal district.

To test this idea, I consider the unlitigated cities in the full and long samples, matching each unlitigated city with a litigated city in the same federal district. ${ }^{36}$ For cases where a single match is available, I assign to the unlitigated city the litigation date of the litigated city. In situations with multiple matches, I assign to the unlitigated city the minimum of the available dates, since that would correspond to the first date as of which an unlitigated city would have been alerted to the possibility of litigation in the district. ${ }^{37}$

This matching procedure generates a sample of unlitigated cities in the full and long samples with neighbor-litigation dates. Some cities are located in a state or sub-state area with no litigated city (e.g., the cities in Rhode Island). These cities play the role of the unthreatened in this analysis and are analogous to the unlitigated in the analysis of the preceding subsections.

Figure 6 presents the event study of the impact of neighbor-litigation on the representation gap. The results are surprisingly inconsistent with a threat effects hypothesis. The post-litigation estimates for the full sample unlitigated cities, given in the top panel, never exceed 0.01. Among unlitigated cities in the long sample, given in the bottom panel of Figure 6, there appears to be very little pre-litigation trend. Post-litigation, the estimated effects for the long sample are negative

\footnotetext{
${ }^{36}$ Some federal districts (e.g., the Northern, Middle, and Southern Districts of Alabama) were consolidated into one state area due to a small number of cities.

${ }^{37}$ Note that if cities respond to the national trend of litigation by integrating, then estimation of threat effects will require that we impose assumptions on the secular black employment share time path in the absence of litigation. I do not consider such assumptions here and so discuss this type of threat effect no further.
} 
rather than the expected positive for both Model 3 and for Model 4.

\section{E. Robustness}

Because the dependent variable in the above estimation is the simple difference between black employment share and city fraction African American, the estimates presented are potentially driven by changes in city demographics, which presumably do not respond to litigation. The most direct way to address this concern is to re-estimate Equation (3) with city fraction African American replacing the representation gap. In results not reported, such estimates are quite small in magnitude (generally below 1 percentage point) and slightly positive in the post-litigation period. For all models, re-estimating Equation (3) with police department black employment share as the dependent variable and including city fraction African American as a control results in a coefficient close to one for city fraction African American. The robustness of the results to the manner in which we control for city fraction African American means that the estimates of the impact of litigation reported in this paper apply equally to the representation gap and to police department black employment share.

While litigation is unrelated to city fraction African American, litigation is related to black and white flight. Re-estimating Equation (3) with the log of city population replacing the representation gap indicates that litigation is associated with roughly a 10 percent decline in city population over 25 years (results not reported).

\section{Litigation and Crime}

The judges intervening in police department hiring practices seem to have had a clear goal of inducing police departments to hire more black officers. It is not inconceivable, however, that an unintended consequence of the effort was more crime. As noted in Section II, above, police department entrance examinations exhibit sizeable black-white test score gaps. It is fairly clear that police department entrance examinations test aptitude, to at least some extent. If these exams successfully isolate aspects of aptitude that are relevant to the job of police officer, then the natural expectation is that hiring quotas with bite would lead to a downgrading in the quality of a police force, as departments are required to hire individuals whose low test scores would otherwise have prevented their selection. 
However, if these exams select applicants on the basis of aspects of aptitude which are irrelevant to police performance, then court-ordered hiring quotas would be of little consequence, except to the extent that more black officers would be hired as a result. It has long been argued that African Americans are more effective crime fighters than other Americans, at least conditional on entrance exam score (e.g., National Advisory Commission on Civil Disorders 1968 (Chapter 11), National Advisory Commission on Criminal Justice Standards and Goals 1973 (pp. 330-333), Decker and Smith 1980, Donohue and Levitt 2001). It is possible that this effect could be strong enough to offset any aptitude differences between applicant groups. Moreover, in Section V.B, I simulate the effect of quota hiring on the test score distribution of new hires, as compared with the traditional mechanism of rank-order hiring, disregarding race. Quantitatively, quota hiring affects entrance exam scores of new cadets only slightly. This suggests that aptitude differences are likely to be small, and that net productivity effects will reflect primarily the crime-fighting ability of the marginally hired African American officer relative to that of the marginally hired individual absent a quota hiring regime.

Litigation might also afford the productivity of incumbent officers through a morale effect. Morale and productivity effects would be expected to manifest themselves at different time horizons. Shortly after litigation, nearly all officers are still incumbents, due to the low police quit rate. Thus, productivity effects should be small and morale effects should predominate. Many years after litigation, much of the workforce will have been replaced with officers hired under the affirmative action regime, and productivity gains or losses should manifest themselves more strongly. At the same time, it is plausible that morale effects dissipate over long time horizons, so that the long-run effect is dominated by productivity considerations. However, as emphasized above, net productivity reflects both the skill content of police department entrance exams and the crime-fighting ability of black officers relative to that of other officers, so the sign of any long-run effect of litigation on police performance is theoretically ambiguous.

Even if litigation does not affect crime, it could affect intermediate aspects of police performance, such as the racial composition of arrests. This issue has been studied by Donohue and Levitt (2001), who conclude that the hiring of black (white) officers increases the number of white (black) arrestees, but leaves unchanged the number of black (white) arrestees. Since litigation results in an increase in black officers at the expense of white officers, their results imply that litigation should 
decrease the number of black arrests and increase the number of white arrests, for a decrease in the fraction black of arrestees. The evidence presented below is consistent with this prediction, but the magnitude of the effect is modest.

The effect of court-ordered affirmative action on crime has also been studied by Lott (2000). Lott considers only affirmative action required by DOJ consent decrees still in place as of 1987, when public-use data on police department black employment share become available. Lott's estimates imply that affirmative action increases crime. Lott emphasizes a specific mechanism, arguing that affirmative action over this period involves reducing standards for applicants generally. This argument is difficult to reconcile with the simulation of Section V.B. Moreover, that mechanism is less plausible in the historical context studied here, where affirmative action typically meant hiring in rank order of test score, stratified by race - in which case no reduction of standards for non-black applicants was required. ${ }^{38}$

The 19 departments still subject to consent decrees as of 1987 are a selected sample, in two different ways, of departments placed under affirmative action obligations. First, they do not include those departments litigated by private actors. Second, they do not include those departments which had already by 1987 complied with any court-ordered affirmative action. These considerations suggest that crime rates in these cities may have as much to do with inflexible management as they do with changes in workforce demographics. My own measure of affirmative action is whether a department was ever subject to litigation alleging hiring discrimination against African Americans. It incorporates litigation brought by both the DOJ and private actors and does not reflect compliance with affirmative action mandates.

\section{A. Descriptive Statistics and Estimation Results}

I begin with a consideration of simple descriptive statistics on crime rates by litigation status and litigation timing. For both the full and long samples, panel $\mathrm{C}$ of Table 1 gives the log crime rate for litigated and unlitigated cities at ten-year intervals beginning in 1960. For the full sample, it appears that crime rates in litigated and unlitigated cities differed by less than ten percent until the

\footnotetext{
${ }^{38}$ If entrance examinations were previously job related and were diluted of their content in order to eliminate disparate impact, then these considerations again become important. While there are undoubtedly examples of test dilution my reading of the history is that the additional pressure to establish a fair and impartial process for deriving test questions related to job performance on net made the examinations more job related rather than less.
} 
1990s, when crime rates fell dramatically in the litigated cities. Among cities in the long sample, the unlitigated had higher crime than the litigated in 1960. However, beginning in 1970 the crime rates in litigated and unlitigated cities have a close correspondence.

Panel C of Table 2 gives the log crime rate for five categories of litigation date ranges at tenyear intervals beginning in 1960. Cities litigated in 1977-1980 have a 1960 crime rate that is 30 percent higher than the estimates for the other four litigation date ranges. Between 1960 and 1970, however, the crime rate in cities that were litigated 1969-1974 and in the 1980s soared relative to that in cities litigated 1977-1980. Between 1970 and 1999, the crime rates in the five city groups appear to move roughly in parallel.

The top panel of Figure 7 gives log crime rates by litigation status for 1960 to 1999 (cf., Figure 1, panel B). As suggested by the ten-year interval data in Table 1, there are no discernible differences between litigated and unlitigated cities on average following the onset of litigation. What differences do exist are concentrated in the years before litigation: during the 1960s, the crime rate in litigated cites grew rapidly relative to unlitigated cities. However, already by 1970 the crime rates had equalized. From 1970 to 1994, crime rates in the two sets of cities are virtually identical. Only with the late 1990s drop in crime do any differences in crime rates emerge. The crime rate differences at the beginning and end of the sample appear to reflect state-by-year specific patterns, and are largely absorbed in the state-by-year controls in the event study analysis below.

At the bottom of the top panel are log policing rates by litigation status. While litigated departments employ more officers per capita than do unlitigated departments, there is no discrenible trend differential in this measure over time. The event study analysis below corroborates this impression.

The top panel of Figure 7 also gives, by litigation status, two additional police performance measures: index arrests per index crime, and the fraction of index crimes cleared. ${ }^{39}$ In principle, both measures proxy a single phenomenon - the rate at which officers are engaging in the apprehension of individuals in a manner coordinated with solving index crimes known to police (as opposed to making many prostitution arrests, for example). However, as noted in Section II, above, the first proxy is taken from two different survey forms, whereas the second proxy is based on information from a single form. This suggests that clearance rates are measured with less error than arrest

\footnotetext{
${ }^{39}$ For viewing purposes, I have added 0.10 to each of the arrest rate series.
} 
rates.

There is remarkable similarity between litigated and unlitigated departments in terms of arrest rates and clearance rates. While arrest rates exhibit a differential litigated-unlitigated trend prior to the era of litigation, this is not confirmed by the data on clearance rates. Indeed, clearance rates corroborate the essential impression conveyed by crime rates: litigated and unlitigated departments delivered roughly similar police performance before, during, and after litigation. The event study estimates below suggest, however, that these broad similarities may potentially mask some modest effect sizes.

The bottom panel of Figure 7 gives the fraction African American among index crime arrestees, separately by litigation status. Litigated departments have always arrested substantially more African Americans than unlitigated departments. There is some convergence in the arrest fraction black beginning in the $1990 \mathrm{~s}$, but the magnitude is small.

With that backdrop, I now turn to event study estimates of the impact of litigation on police performance. To economize on space, I present event study graphs only for the more interesting results. Panel A of Figure 8 gives event study estimates of the impact of litigation on city crime rates. These estimates are not consistent with a major impact of black police on crime rates, although the evident noise in the crime series means it is difficult to detect small effect sizes.

Panel B of Figure 8 gives event study estimates for the clearance rate. While the point estimates are generally insignificant (including the pre-litigation estimates and the longer litigation lags), there is a statistically significant drop in clearance rates in litigated departments 5 to 7 years after litigation. ${ }^{40}$ The timing of the effects is consistent with turmoil in the department. Quotas were typically imposed in these cases 1 to 3 years after the filing date of litigation, and the decline in clearances is precipitous at 3 years after litigation. However, because affirmative action continued to affect hiring in departments throughout the study period, the timing of these effects is not consistent with net productivity differences between affirmative action hires and incumbents, as the effects dissipate after a handful of years.

Panel $\mathrm{C}$ of Figure 8 gives event study estimates for the fraction of index crime arrestees who are African American. This series is particularly noteworthy, since the timing of the effects is consistent

\footnotetext{
${ }^{40}$ For example, Model 1 estimates have t-ratios of $-3.45,-2.32$, and -2.29 , and Model 4 estimates have t-ratios of $-3.25,-3.59$, and -3.24 . Estimates from Model 4 are significant in years 3 through 13.
} 
with the gains in black employment share. As noted by Donohue and Levitt (2001), the effect of the racial composition of the police on the racial composition of arrests could reflect many factors, including changes in the probabilities of false arrest (presumably due to information processing) and changes in the probabilities of true arrests (presumably due to officer tastes or corruption). ${ }^{41}$

Table 4 summarizes the long-run trends in these outcomes, as well as for log police per 100,000 populuation, the arrest rate, and the fraction black among all arrestees. Both the post-litigation trend and the break in trend at the litigation filing data are reported. The point estimates in the table are generally small and insignificant. An important exception is the estimate for the fraction black among index crime arrestees, which is suggestive of effects of affirmative action on intermediate aspects of police performance. ${ }^{42}$

\section{B. The Distribution of Entrance Exam Scores by Race}

I next present evidence on the temporal evolution of the distribution of entrance examination scores by race for the New York City Police Department. These data allow direct calculation of the difference in the distribution of test scores of newly hired officers under various hiring rules. For example, it is possible to calculate the distribution of test scores under the rank-order hiring rule traditionally used by police departments, and we may compare this distribution directly with the distribution of test scores which would result if an aggressive hiring quota were imposed. These two distributions turn out to be rather similar, suggesting a limited role for the hypothesis that quotas increase crime by circumventing standards.

I have been able to obtain information on the distribution of test scores by race for the 1968, 1970, 1979, and 1998-99 examinations. ${ }^{43}$ For all examinations for which I have data, Table 5 gives the fraction of white and black applicants with scores in each decile of the overall test score distribution. The numbers in the Table suggest that in both the 1968 and 1970 examinations, African Americans constituted roughly 5 percent of those in the upper three deciles and 20 percent of all applicants.

In 1972, the Guardians Association and the Hispanic Society of the NYCPD mounted a legal

\footnotetext{
${ }^{41}$ These are not the only effects discussed by Donohue and Levitt (2001), but the other other key effects are transmitted through impacts on crime. The results below indicate that the impact of litigation on crime is modest and perhaps zero.

${ }^{42}$ Note as well that the temporary decline in clearance rates is not captured by long-run trends.

${ }^{43}$ See Appendix I.
} 
challenge to these examinations. The court found that the city was in violation of Title VII because the exams were insufficiently job-related; however, the case was declared moot because of the mid1970s fiscal crisis, which was to preclude hiring in the NYCPD for a period of several years. When the City was again in a financial position to contemplate hiring, in 1979, the Personnel Department went to great lengths to design an exam that was job related:

Exam No. 8155 is a "second generation" selection procedure. Despite the various flaws in construction of the test, it is clear that some attempt was made to develop the test with recognition of at least some of the standards that courts had established in the first wave of Title VII cases. Aware that the validity of the test would likely have to be demonstrated, the City performed an extensive job analysis, consciously used concepts [from the EEOC Uniform Guidelines on Employee Selection Procedures] in determining the qualities that were being tested for, and attempted to eliminate extraneous variables, such as the applicant's prior knowledge, his reading level, and his ability to complete the test in a relatively short amount of time. ${ }^{44}$

However, after the test was administered, the Guardians again challenged the test under Title VII, because this test - although it exhibited less disparate impact than the 1968 and 1970 examscontinued to pass whites at a much higher rate than African Americans. For example, non-whites constituted only 18 percent of those among the top three deciles, despite being 34 percent of applicants.

Interestingly, the black-white test score gap on the NYCPD entrance exam does not appear to have changed much since 1979. Figure 9 gives separate histograms for whites, and for African Americans and Latinos combined, for the 1979 and 1998-99 examinations. Due to the extremely large sample sizes, and the fact that the support of test scores is discrete, the histogram requires no smoothing. Brief inspection of the figure reveals that although there are substantial differences between the test score distributions for whites and non-whites, there are virtually no differences in the white test score distribution over time, and the non-white test score distribution over time.

Using the data underlying Figure 9, it is a simple matter to simulate the impact of quota hiring on the distribution of test scores among the newly hired. For example, from the 1979 exam, the NYCPD anticipated that all those with scores of at least 94 would move on to the next phase in the selection process. Thus, all new hires were, in the absence of court intervention, to be drawn from the extreme upper tail of the test score distribution. The range of scores would have naturally been

\footnotetext{
${ }^{44} 630$ F. 2d $79,89$.
} 
from a low of 94 to a high of 110, with an average score of 96.8. In 1980, in response to the evidence regarding the difference in the distribution of test scores by race, the district court judge ordered that 50 percent of new hires be African American or Latino. ${ }^{45}$ I estimate that a cohort selected under this aggressive quota would have had scores ranging from 87 to 110 and an average of 95.3. Thus, it appears that even with an aggressive hiring quota and a visually discernible difference in test score distributions, the average qualifications of an entering cohort would only be affected in relatively minor ways. While it is possible that one bad apple spoils the bunch, the most natural model of the effect of police officer quality on crime posits that crime depends on the sum of officers' test scores. If this is the right model, then even the most aggressive affirmative action measures would not be expected to affect city crime rates through effects on the distribution of aptitude among entering cohorts.

\section{Conclusion}

This paper has examined the impact of class action employment discrimination litigation on black employment share and police performance in 314 large municipal police departments. Regarding the impact of litigation on black employment share, the evidence points to several key conclusions. First, the litigation of the 1970s was targeted at big cities with large and growing African American populations and low black employment share. Second, despite substantial initial differences between litigated and unlitigated cities, by 1999 litigated cities' representation gap was largely equal to that of unlitigated cities. Third, this convergence appears to have occurred almost entirely in the years following litigation. Fourth, although unlitigated cities with large initial representation gaps exhibit more convergence than cities with small gaps, this pattern is not strong enough to account for the gains accruing to litigated cities. Fifth, there is little evidence supporting a threat effect hypothesis. In particular, litigated cities do not appear to exhibit any gains in black employment share prior to litigation, and unlitigated cities do not appear to integrate following the filing of the first class action employment discrimination suit in their state.

On the whole, I interpret the evidence summarized in this paper as consistent with a major role for the federal courts in integrating police departments in the United States. My best estimate

\footnotetext{
${ }^{45}$ Guardians Association of the New York City Police Department v. New York City Police Department, 484 F. Supp. 785, 799 (S.D. New York, 1980). This example is for illustrative purposes only; the 50 percent hiring quota was subsequently softened by the appeals court. 630 F. 2d 79.
} 
of the 25-year gain in police department black employment share is 10 percentage points, and the effect is estimated with some precision. Because of the low attrition rate of police officers, this is consistent with a hiring fraction African American roughly 14 percentage points above the pre-litigation police department fraction black.

In contrast to the estimated impact of litigation on police department black employment share, I find little evidence of an impact of litigation on crime. This may be because of a complex series of effects that offset one another. For example, there is some evidence that litigation led to turmoil in the department, temporarily reducing clearance rates, which presumably encouraged crime. However, this effect on crime is not detectable, perhaps because African American officers are more productive crime fighters than other Americans.

The analysis in this paper rules out one mechanism by which litigation might have been expected to affect crime. Police departments' standard practice is to hire in rank order by test score, and judges handing down quotas typically allowed departments to continue to do so, but required that they do so separately by race. Using data on test score distributions in New York City, thought to be representative of those for all police departments, I show that in such a context, even aggressive hiring quotas change the test score distribution of new hires only minimally. This suggests that the magnitude of any aptitude differences induced by quota hiring is small, even for long-term quota hiring regimes. Unless African Americans fare much better on the New York City Police Department entrance examinations than on the entrance examinations of other cities, these conclusions would seem to hold for police departments generally. 


\section{Appendix I. Data}

Sample of Cities: The 314 cities for study were selected from among those U.S. municipalities with the largest police and fire departments, on the basis of the Census of Governments from 1972, 1977, 1982, 1987, 1992, and 1997. The specific mechanism for selection was as follows. First, I merged the employment counts by function of government for all municipal respondents in the above years. Average employment levels over the period were computed. There were 328 cities whose average police and fire employment levels placed them in the top 400 nationally of both categories. These cities were then sought in the electronic files of the EEO-4 survey. Satisfactory data for 314 cities was available. Most of the cities unable to be matched are quite small. However, Washington, D.C. and San Francisco were excluded from the analysis because survey responses from these cities were not available until the 1980s. ${ }^{46}$ The resulting sample is comprised of 314 cities in all nine Census regions, and in all but the least populated of the 48 contiguous states. ${ }^{47}$

Black Police Officer Data: Data on police department demographics are obtained primarily from the EEO-4 survey of the Equal Employment Opportunity Commission (EEOC), conducted annually by the EEOC since $1973 .{ }^{48}$ These data are confidential, but may be made available to researchers. Tabulations of these data have typically been published by the EEOC and are available in libraries (see, for example, Equal Employment Opportunity Commission 1999). Previous researchers have been able to access electronic files for 1980, 1984, 1985, 1987, 1989, 1990, 1991, 1993, 1995, 1997, and 1999. As part of the research for this study, I traveled to the EEOC and recovered the 1973 and 1974 surveys. Electronic files in EBCDIC and packed decimal format were available, but codebooks were not. Aided by the institutional knowledge of Ron Edwards, I inferred a codebook for these data and constructed electronic files. In EEOC headquarters, I located several 9 track reels containing the only known copies of the 1982 EEO-4 survey. Unfortunately, these reels, had experienced a high degree of physical degradation, and only half of the records from the 1982 survey are available. In the Alexandria warehouse of the EEOC, I located microfilm records for 1975, 1977, and 1981. A team of research assistants entered these data for all cities (1975 and 1977) and for those cities missing 1980 records (1981). The 1981 records are important, since large cities are systematically missing in $1980 .{ }^{49}$ The city identifiers assigned by the EEOC had a small number of errors for the years 1980 to 1999, which I corrected manually using name and address information for each city. Identifiers for 1973 and 1974 also do not conform to the 1980 identifiers; for these years, I created a full crosswalk for all identifiers.

Because the first EEO-4 survey was not conducted until 1973, further data on the number of African American officers in police departments were collected from several historical sources. The most nationally comprehensive International City Manager Association (1970), which details the number of "minority group employees-uniformed". I interpret these numbers as the number of African American and Latino officers and have discounted them by the estimated 1973 fraction of African American and Latino officers that were African American. The other nationally comprehensive survey comes from unpublished research (Raper 1940) on "Negro policemen" upon which

\footnotetext{
${ }^{46}$ The fire and police departments of San Francisco were litigated in 1970 and 1973, respectively. The police department of Washington, D.C. was litigated in 1970.

${ }^{47}$ Montana, North Dakota, Vermont, and Wyoming are all unrepresented. The 2000 population ranks of these states among the 48 contiguous states are $43,46,47$, and 48 , respectively.

${ }^{48}$ Beginning in 1991, the EEOC has conducted the EEO-4 survey only once every two years. The 1972 Equal Employment Opportunity Act granted authority to the EEOC to collect data from public employers, expanding the EEOC's older data collection authority regarding private employers (conferred by the 1964 Civil Rights Act).

${ }^{49}$ For example, neither New York nor Los Angeles is included in the 1980 file. The source of this problem appears to be that electronically submitted returns were ironically not included in the electronic file compiled by the contractor for the 1980 survey. Data for cities located on the same microfilm reel as a city with missing data were also included.
} 
Myrdal (1944) relied. ${ }^{50}$ Raper's research led to surveys of Southern police departments spanning 1947 to 1969. Raper was a longtime writer for the Commission on Interracial Cooperation, which the Southern Regional Council (SRC) succeeded in 1944. From 1947 to 1954, the SRC continued Raper's surveys of the number of "Negro uniformed policemen, detectives (plainclothes), and policewomen" for Southern municipalities, publishing results annually in New South. ${ }^{51}$

Publication of these numbers ceased after 1954, as the SRC focused its efforts on school desegregation and voter registration (Rudwick 1961). However, Elliott Rudwick conducted surveys of Southern police departments in 1954, 1959, and 1961 and the SRC published the results in Rudwick (1962). Then, in 1969, the SRC attempted what was to be its final survey of Southern police departments. The results of the survey were not published, but the data are available in recently published microfilm records Southern Regional Council (2000, Reel 111(434), pp. 289-298).

For non-Southern cities, data on the number of "Negro police" in 1954 for a small number of cities are published in Kephart (1954) and Kephart (1957). Data on larger cities' black employment share have also been published in the reports of several presidential and gubernatorial commissions: President's Commission on Law Enforcement and Administration of Justice (1967), National Advisory Commission on Civil Disorders (1968), and National Advisory Commission on Criminal Justice Standards and Goals (1973). Finally, it appears that the U.S. Commission on Civil Rights conducted a survey of employment of African American police officers in 230 departments in 1962 (President's Commission on Law Enforcement and Administration of Justice 1967, pp. 167-168). However, the Commission did not publish this work, the Commission Library does not possess a copy, and the survey results are not part of the holdings of the National Archives' holdings of the Commission's papers. I believe this is the only nationally comprehensive survey information on the employment of black police officers not included in the data used for this study.

The historical sources consulted allowed estimation of 1969 black employment share for all 314 cities under study. Because litigation began in 1969, this is an important aspect of the data collection undertaken here. For a subset of 120 cities, referred to in the body of the text as the "long sample," data on black employment share for 1960 to 1969 are available.Data on black employment share were combined with data on city fraction African American (linearly interpolated between Census years).

I also use an administrative data set on police officers in the Chicago Police Department (CPD), provided to me by Adam Kingsley of the City of Chicago Department of Law following a records request. The data set contains, for every individual who has worked for the CPD since approximately the late 1970s, a hiring date, a termination date, race and other information not used here. Details on the construction of this data set from CPD administrative records is provided in Siskin and Griffin (1997). I use these data to construct a sample of CPD police officers for all years from 1960-1997. Using the Uniform Crime Reports (UCR), I estimated the sampling rate for each of these extracts. From a low of 40 percent in 1960, the rate rises smoothly in time, arriving at a constant level 95-105 percent beginning in 1977. The sampling rate for African American officers is higher than that of other officers for the early years (sources on black police available for 1962, 1967, and 1969). I estimate the black sampling rate in these years to be 80,76 , and 70 percent. These rates are to be compared to the overall rates of 50,65, and 71 percent, respectively. The downward trend in Figure 1 in hiring fraction African American pre-1970 is likely an artifact of this phenomenon, but the 1974 spike may not be attributed to this because the sampling rates were

\footnotetext{
${ }^{50}$ Comparing 1930 and 1940 Census published totals of African American police officers with Raper's estimates suggests that Raper identified the employers of some 90 percent of the black police officers in the country.

${ }^{51}$ Outline of volumes used: October 1947, Vol. 2, No. 10, p. 9; September 1948, Vol. 3, No. 9, p. 7; September 1949, Vol. 4, No. 9, p. 9; September-October 1950, Vol. 5, Nos. 9 and 10, p. 6; September 1952, Vol. 7, No. 9, p. 6; and October-November 1953, Vol. 8, Nos. 10 and 11, pp. 6-7.
} 
similar already in 1969.

Litigation Data: To learn which cities were litigated, I read over 1,300 published decisions in which hiring discrimination against African Americans on the part of the city police or city fire department was alleged. ${ }^{52}$ These decisions were located in a multi-step process. First, for all 314 cities under study, a keyword search on "discrimination", "black", and "police" / fire" was conducted in conjunction with the name of the city (e.g., "Norfolk"). Second, the resulting list of cases was scanned and those deemed potentially relevant were selected for skimming. In the third step, decisions determined to pertain to discrimination against either the police or fire department in the city were read in their entirety (preliminary research indicated that judges in fire department cases frequently mention litigation against the police department in the same city). Fourth, all cases cited by each of those decisions as pertaining to discrimination cases were consulted. Two pieces of evidence suggest that this strategy led to a relatively complete record of the litigation. First, only a handful of cases identified in the fourth step had not been already been located using keyword searches. Second, the cases listed in U.S. Department of Justice (2001) are a strict subset of the cases located by the first search method.

It was not possible to determine which departments were subject to quotas during which time periods. Because of unpublished decisions and judicial choices regarding what to discuss in the text of an opinion, information on quotas is much more poorly measured than whether a city was litigated, and the date as of which the litigation began. Litigation filing dates were determined by reference to the first two digits of the Civil Action Number (CAN) for located cases. Because litigation filing dates are embedded in the CAN, the location of even one published decision pertaining to a case results in knowledge of the filing year.

Crime Data: Data on crime and police staffing were obtained from the Uniform Crime Reports available from the Inter-university Consortium for Political and Social Research (ICPSR) for 1975 to 1999. Data prior to 1975 are not available from ICPSR, but are available from the Federal Bureau of Investigation. ${ }^{53}$

Entrance Exam Data: The 1968 and 1970 data are from Chaiken and Cohen (1973). The 1979 data are from Guardians Association of the New York City Police Department v. the New York City Police Department, 630 F. 2d 79, 103 (2nd Cir., 1980). The 1998-99 data were obtained from the New York City Police Department following a records request.

City Demographics Data: City demographics such as fraction African American and population were taken from the population censuses for 1960, 1970, 1980, 1990, and 2000, and linearly interpolated between census years. Electronic files were available for all years except for 1960, where I substituted published tabulations. ${ }^{54}$

Riot Data: Data on riots 1961 to 1968 are taken from the Data and Program Library Service at the University of Wisconsin.

Availability of Data: A series of electronic files containing all data and programs used for this paper are available for researchers with access to EEOC data files. Interested researchers should contact Ron Edwards at the EEOC.

\footnotetext{
${ }^{52}$ Interested researchers may obtain additional records (e.g., unpublished decisions and consent decrees) on the cases studied here by contacting the federal district court in which the case originated. That strategy was not pursued here due to cost.

${ }^{53}$ These files were obtained with the help of Joanne Vanatta of the Programs Support Section of the FBI, Ron Edwards of the EEOC, and Rick Kawin of UC Berkeley.

${ }^{54}$ For 1970, information in the electronic file was missing for East Hartford and West Hartford, Connecticut, and Brookline, Massachusetts, and published tabulations were again used.
} 


\section{Appendix II. Using Quit Rates to Predict Changes in Hiring Practices}

This appendix justifies the approximation in (1). Let $N_{t}^{B}$ and $N_{t}$ denote the number of black and all officers, respectively, at time $t ; H_{t}$ the number of officers hired between $t-1$ and $t ; q_{t}^{B}$ the quit rate of black officers; and $f_{t}$ the hiring fraction African American. The identity

$$
N_{t}^{B}=N_{t-1}^{B}-N_{t-1}^{B} q_{t-1}^{B}+H_{t} f_{t}
$$

states simply that the number of black officers in period $t$ is equal to the number of black officers in period $t-1$, less the number of black officers quitting, plus the number of black officers hired. Dividing both sides by the number of total officers implies

$$
\begin{aligned}
F_{t} & =\frac{N_{t}^{B}}{N_{t}}=\frac{N_{t-1}^{B}}{N_{t}}\left(1-q_{t-1}^{B}\right)+\frac{H_{t}}{N_{t}} f_{t}=\frac{N_{t-1}^{B}}{N_{t-1}} \frac{N_{t-1}}{N_{t}}\left(1-q_{t-1}^{B}\right)+\frac{H_{t}}{N_{t}} f_{t} \\
& =\frac{1-q_{t-1}^{B}}{1+\varepsilon_{t}} F_{t-1}+h_{t} f_{t} \\
& \equiv \gamma_{t-1} F_{t-1}+h_{t} f_{t}
\end{aligned}
$$

where $\gamma_{t-1}=\left(1-q_{t-1}^{B}\right) /\left(1+\varepsilon_{t}\right), h_{t}$ is the new hires rate and, as in the main text, $F_{t}$ denotes the black employment share in period $t$ and $\varepsilon_{t}$ is the year-over-year growth rate in the size of the workforce (i.e., $\left.\varepsilon_{t}=\left(N_{t}-N_{t-1}\right) / N_{t-1}\right)$. Iterating on this recursion yields

$$
F_{t}=\Gamma_{t, k} F_{t-k}+\sum_{j=0}^{k-1} \Gamma_{t, j} h_{t-j} f_{t-j}=\Gamma_{t, k} F_{t-k}+\bar{h} \bar{f} \sum_{j=0}^{k-1} \Gamma_{t, j}+\widehat{C}\left[h_{t-j}, f_{t-j}\right] \sum_{j=0}^{k-1} \Gamma_{t, j}
$$

where $\Gamma_{t, j}=\prod_{i=1}^{j} \gamma_{t-i}$ for $j>0$ and $\Gamma_{t, j}=1$ for $j=0, \widehat{C}\left[h_{t-j}, f_{t-j}\right]$ is the weighted covariance of the hiring fraction African American and the hiring rates over the past $k$ periods, $\bar{h}$ is the weighted average of hiring rates, and $\bar{f}$ is the weighted average of the hiring fraction African American, with weights proportional to $\Gamma_{t, j}$ and summing to one.

I now consider simplifying assumptions designed to allow something meaningful to be said about the likely fraction African American among new hires, given information solely on gains in the black employment share and an estimate of the quit rate. Two assumptions which are sufficient are

A1. Quit Rates, Hiring Rates, and the Hiring Fraction African American are Constant: $q_{\tau}=\bar{q}, h_{\tau}=\bar{h}$, and $f_{\tau}=\bar{f}$, for $\tau \in\{t-k, t-k+1, \ldots, t-1, t\}$.

A2. Black Quit Rates are Equal to Overall Quit Rates: $q_{\tau}^{B}=q_{\tau}$ for $\tau \in\{t-k, t-k+1, \ldots, t-1, t\}$.

Since $h_{t} \equiv\left(\varepsilon_{t}+q_{t-1}\right) /\left(1+\varepsilon_{t}\right)$, Assumptions A1 and A2 imply $\varepsilon_{t} \equiv \bar{\varepsilon}$, leading to the identity

$$
F_{t}=\left(\frac{1-\bar{q}}{1+\bar{\varepsilon}}\right)^{k} F_{t-k}+\left\{1-\left(\frac{1-\bar{q}}{1+\bar{\varepsilon}}\right)^{k}\right\} \bar{f}
$$

which we recognize as (1). Letting $\alpha=\left(\frac{1-\bar{q}}{1+\bar{\varepsilon}}\right)^{k}$, we have

$$
\bar{f}-F_{t-k}=\frac{1}{1-\alpha}\left(F_{t}-F_{t-k}\right)
$$


which we recognize as the conversion Equation (2). An alternative set of sufficient assumptions is also available, recorded here as B1 through B3:

B1. Black Quit Rates and Employment Growth Rates are Small: $q_{\tau}^{B}$ and $\varepsilon_{\tau}$ are near zero for each $\tau \in\{t-k, t-k+1, \ldots, t-1, t\}$

B2. Hiring Rates and the Hiring Fraction African American are Uncorrelated: $C\left[h_{\tau}, f_{\tau}\right]=0$ for $\tau \in\{t-k, t-k+1, \ldots, t-1, t\}$.

B3. Law of Large Numbers:

$q_{t}, q_{t}^{B}$, and $h_{t}$ are covariance stationary and jointly ergodic, and $k$ is large.

Assumptions B1 and B3 imply that A1 holds approximately. For example, a second-order Taylor approximation for $\ln (1+x)$ shows that

$$
\Gamma_{t, k}=\exp \left(-k\left\{\bar{q}^{B}+\bar{\varepsilon}\right\}\right) \exp \left(\frac{1}{2} k\left\{\widehat{V}\left[q_{t-i}^{B}\right]+\left(\bar{q}^{B}\right)^{2}\right\}\right) \exp \left(\frac{1}{2} k\left\{\widehat{V}\left[\varepsilon_{t-i}\right]+(\bar{\varepsilon})^{2}\right\}\right)+\widetilde{o}
$$

where $\widetilde{o}$ is a general representation for an error which is (here, to second-order) small when black quit rates and employment growth rates are small, and now $\bar{q}$ and $\bar{\varepsilon}$ denote the simple averages of quit and employment growth rates, respectively. ${ }^{55}$ Under B3, the terms $\frac{1}{2} k\left\{\widehat{V}\left[q_{t-i}^{B}\right]+\left(\bar{q}^{B}\right)^{2}\right\}$ and $\frac{1}{2} k\left\{\widehat{V}\left[\varepsilon_{t-i}\right]+(\bar{\varepsilon})^{2}\right\}$ are small if quit rates are small relative to $k$, leading to $\Gamma_{t, k} \approx\left(\left(1-\bar{q}^{B}\right) /(1+\bar{\varepsilon})\right)^{k}$ (another Taylor expansion shows this is approximately equal to the the first factor in (5)).

To assess the numerical accuracy of this approximation, consider a simulation with parameters relevant for the context of this paper. Suppose $k=25, q_{t}^{B}$ is distributed uniformly between 0.03 and 0.05 , and $\varepsilon_{t}$ is distributed uniformly beween 0.005 and 0.015 . Then $\left(\left(1-\bar{q}^{B}\right) /(1+\bar{\varepsilon})\right)^{k}$ has an average percentage error for $\Gamma_{t, k}$ of 5.2 percent, with a near perfect correlation. ${ }^{56}$

Since the weights $\Gamma_{t, j}$ are bounded, assumptions B2 and B3 imply that $\widehat{C}\left[h_{t-j}, f_{t-j}\right] \stackrel{p}{=} 0$, and assumption B3 and Slutsky's theorem imply that $\bar{h} \stackrel{p}{=}(\bar{\varepsilon}+\bar{q}) /(1+\bar{\varepsilon})$, where $A_{k} \stackrel{p}{=} B_{k}$ means that $A_{k}$ and $B_{k}$ share a probability limit. This leads to

$$
F_{t} \stackrel{p}{=}\left(\frac{1-\bar{q}^{B}}{1+\bar{\varepsilon}}\right)^{k} F_{t-k}+\frac{\bar{\varepsilon}+\bar{q}}{\bar{\varepsilon}+\bar{q}^{B}}\left\{1-\left(\frac{1-\bar{q}^{B}}{1+\bar{\varepsilon}}\right)^{k}\right\} \bar{f}+\widetilde{o}
$$

(cf., (1)). Letting $\alpha=\left(1-\bar{q}^{B}\right) /(1+\bar{\varepsilon})$ and $\delta=(\bar{\varepsilon}+\bar{q}) /\left(\bar{\varepsilon}+\bar{q}^{B}\right)$, we obtain

$$
\delta \bar{f}-F_{t-k} \approx \frac{1}{1-\alpha}\left(F_{t}-F_{t-k}\right)
$$

(cf., (2)). This implies that $\frac{1}{1-\alpha}\left(F_{t}-F_{t-k}\right)$ will understate the regime-shift in the hiring fraction African American if $\bar{q}^{B}>\bar{q}$ and will overstate the regime-shift if $\bar{q}^{B}<\bar{q}$.

In the text, I implement this approximation technique using a year-over-year growth rate estimate of 1 percent and a quit rate of 4 percent. While the year-over-year growth rate is observed directly, the quit rate is not. However, 4 percent is in line with the available evidence. The Chicago

\footnotetext{
${ }^{55}$ Note that since the $\Gamma_{t, k}$ are bounded, under B3, the simple and weighted averages are equal in probability.

${ }^{56}$ On average across 10,000 replications, $\left(\frac{1-\bar{q}^{B}}{1+\bar{\varepsilon}}\right)^{k}$ was 0.281 , while $\Gamma_{t, k}$ was 0.267 . The overstatement is attributable to quit rates being generally larger than employment growth rates in the chosen example.
} 
data described in Section III yield an estimated quit rate of 3.6 percent. ${ }^{57}$ Butterfield (2001) notes that "[i]n New York City, more than 1,700 officers left the 41,000-member force last year through retirement or resignation, a third more than the year before." (Implied quit rate estimates of $1700 / 41000 \doteq 0.041$ and $1275 / 41000 \doteq 0.031$. $)$ More historically, the District Court of the Eastern District of Pennsylvania reports that "[a]s of September 22, 1972 there were 8,082 members of the [Philadelphia] Police Department ... [D]efendants estimate that 96 persons presently employed on the Police Force will no longer be employed on the Police Force as of January 1, 1973." (Estimate of $96[365 /(8+31+30+31)] / 8082 \doteq 0.043.)^{58}$

Further corroboration of this quit rate estimate is available from the 1991-1992 Police Use of Force survey (Pate and Fridell 1994), which reports average years of service among several hundred large municipal police departments to be 11.3. If $T$ denotes completed time of service, then to maintain a constant workforce size, a department will hire $1 / T$ of its workforce at each point in time, and among those working, average time of service will be $\int_{0}^{T} x \frac{1}{T} d x=\frac{T}{2}$. Thus, 11.3 average years of service among current workers translates into average completed years of service of 22.6 - or a quit rate of about $1 / 22.6 \doteq 0.044$. This estimate is likely slightly overstated, because $T>2 \cdot 11.3$ in a growing department, since entering cohorts must become progressively larger.

\section{References}

Altonji, Joseph and Rebecca Blank, "Race and Gender in the Labor Market," in Orley Ashenfelter and David E. Card, eds., The Handbook of Labor Economics, Vol. 3C, Amsterdam: Elsevier, 1999 .

Antonovics, Kate L. and Brian G. Knight, "A New Look at Racial Profiling: Evidence from the Boston Police Department," NBER Working Paper \#10634, July 2004.

Ashenfelter, Orley and James J. Heckman, "Measuring the Effect of an Antidiscrimination Program," in Orley Ashenfelter and James Blum, eds., Evaluating the Labor-Market Effects of Social Programs, Princeton: Industrial Relations Section, Princeton University, Research Report Series No. 120, 1976, pp. 46-84.

Beller, Andrea H., "The Economics of Enforcement of An Antidiscrimination Law: Title VII of the Civil Rights Act of 1964," Journal of Law and Economics, October 1978, 21 (2), 359-380.

Bowen, William G. and Derek Bok, The Shape of the River: Long-Term Consequences of Considering Race in College and University Admissions, Princeton: Princeton University Press, 1998.

Brown, Charles, "Black-White Earnings Ratios Since the Civil Rights Act of 1964: The Importance of Labor Market Dropouts," Quarterly Journal of Economics, February 1984, 99 (1), 31-44.

Butterfield, Fox, "City Police Work Losing Its Appeal and Its Veterans," New York Times, July $30,2001$.

Carrington, William J., Kristin McCue, and Brooks Pierce, "Black-White Wage Convergence: The Role of Public Sector Wages and Employment," Industrial and Labor Relations Review, April 1996, 49 (3), 456-471.

\footnotetext{
${ }^{57}$ For the sample of officers in the force between 1979 and 1997. Before 1979, it appears that the quit rate is artificially low due to the sampling scheme.

${ }^{58} 348$ F. Supp. 1084, 1110 (E.D. Pa. 1972).
} 
Chaiken, Jan M. and Bernard Cohen, Police Civil Service Selection Procedures in New York City: Comparison of Ethnic Groups, New York: New York Rand Institute, 1973.

Cohen, Bernard and Jan M. Chaiken, Police Background Characteristics and Performance: Report Prepared for the National Institute of Law Enforcement and Criminal Justice, New York: New York Rand Institute, 1972.

Davidson, James, Stochastic Limit Theory: An Introduction for Econometricians, New York: Oxford University Press, 1994.

Decker, Scott H. and Russell L. Smith, "Police Minority Recruitment: A Note on its Effectiveness in Improving Black Evaluations of Police," Journal of Criminal Justice, 1980, 8 (6), 387-393.

DiNardo, John, Nicole Fortin, and Thomas Lemieux, "Labor Market Institutions and the Distribution of Wages, 1973-1992: A Semi-Parametric Approach," Econometrica, 1996, 64 (5), 1001-1044.

Donohue, John J., III and James J. Heckman, "Continuous Versus Episodic Change: The Impact of Civil Rights Policy on the Economic Status of Blacks," Journal of Economic Literature, December 1991, 29 (4), 1603-1643.

Donohue, John J. III and Steven D. Levitt, "The Impact of Race on Policing and Arrests," Journal of Law and Economics, October 2001, 44 (2), 367-394.

Dulaney, W. Marvin, Black Police in America, Indianapolis: Indiana University Press, 1996.

Equal Employment Opportunity Commission, Job Patterns for Minorities and Women in State and Local Government, Washington, D.C.: EEOC, 1999.

Freeman, Richard B., "Changes in the Labor Market for Black Americans, 1948-1972," Brookings Papers on Economic Activity, 1973, 1973 (1), 67-131.

Graham, Hugh Davis, The Civil Rights Era: Origins and Development of National Policy, 19601972, New York: Oxford University Press, 1990.

Greisinger, George, Jeffrey S. Slovak, and Joseph J. Molkup, Civil Service Systems: Their Impact on Police Administration, Washington, D.C.: U.S. GPO, 1979.

Guryan, Jonathan, "Desegregation and Black Dropout Rates," American Economic Review, September 2004, 94 (4), 919-943.

Heckman, James J. and Kenneth Wolpin, "Does the Contract Compliance Program Work? An Analysis of Chicago Data," Industrial and Labor Relations Review, July 1976, 29 (4), 544-564.

, Hidehiko Ichimura, Jeff Smith, and Petra Todd, "Characterizing Selection Bias Using Experimental Data," Econometrica, September 1998, 66 (5), 1017-1098.

International City Manager Association, Municipal Yearbook, Washington, D.C.: ICMA, 1970.

Jacobson, Louis S., Robert J. LaLonde, and Daniel G. Sullivan, "Earnings Losses of Displaced Workers," American Economic Review, September 1993, 83 (4), 685-709.

Jencks, Christopher and Meredith Phillips, The Black-White Test Score Gap, Washington, D.C.: Brookings Institution, 1998. 
Kephart, William, "The Integration of Negroes Into the Urban Police Force," Journal of Criminal Law, Criminology, and Police Science, September-October 1954, 45, 325-333.

__ Racial Factors and Urban Law Enforcement, Philadelphia: University of Pennsylvania Press, 1957.

Knowles, John, Nicola Persico, and Petra Todd, "Racial Bias in Motor Vehicle Searches: Theory and Evidence," Journal of Political Economy, February 2001, 109 (11), 203-229.

Landy, Frank J., "Phases of Employment Litigation," in Frank J. Landy, ed., Employment Discrimination Litigation: Behavioral, Quantitative, and Legal Perspectives, San Francisco: JosseyBass, 2005, chapter 1.

Leonard, Jonathan S., "Antidiscrimination or Reverse Discrimination: The Impact of Changing Demographics, Title VII, and Affirmative Action on Productivity," Journal of Human Resources, Spring 1984, 19 (2), 145-174.

, "The Impact of Affirmative Action on Employment," Journal of Labor Economics, October 1984, 2 (4), 439-463.

_ _ "Affirmative Action as Earnings Redistribution: The Targeting of Compliance Reviews," Journal of Labor Economics, July 1985, 3 (3), 363-384.

_ , "The Impact of Affirmative Action Regulation and Equal Employment Law on Black Employment," Journal of Economic Perspectives, Autumn 1990, 4 (4), 47-63.

Lott, John R. Jr., "Does a Helping Hand Put Others at Risk? Affirmative Action, Police Departments, and Crime," Economic Inquiry, April 2000, 38 (2), 239-276.

Myrdal, Gunnar, An American Dilemma: The Negro Problem and Modern Democracy, New York: Harper and Row, 1944.

National Advisory Commission on Civil Disorders, Report of the National Advisory Commission on Civil Disorders, Washington, D.C.: GPO, 1968.

National Advisory Commission on Criminal Justice Standards and Goals, Report on Police, Washington, D.C.: GPO, 1973.

Pate, Antony M. and Lorie E. Fridell, "Police Use of Force: Official Reports, Citizen Complaints, and Legal Consequences, 1991-1992," 1994. [computer file]. Washington, D.C.: Police Foundation.

President's Commission on Law Enforcement and Administration of Justice, Task Force Report: The Police, Washington, D.C.: GPO, 1967.

Raper, Arthur, "Race and Class Pressures," 1940. Unpublished manuscript. Schomburg Center for Black Culture, New York Public Library.

Reber, Sarah, "Court-Ordered Desegregation: Successes and Failures in Integrating American Schools Since Brown," 2003. Unpublished manuscript. University of California, Los Angeles.

Reiss, Michael, "Requiem for an 'Independent Remedy': The Civil Rights Acts of 1866 and 1871 as Remedies for Employment Discrimination," Southern California Law Review, 1977, 50, 961-1025. 
Rose, David L., "Twenty-Five Years Later: Where Do We Stand on Equal Employment Opportunity Law Enforcement?," Vanderbilt Law Review, 1989, 42, 1121-1181.

Rosen, Sherwin, "Trade Union Power, Threat Effects, and the Extent of Organization," Review of Economic Studies, April 1969, 36 (2), 185-196.

Rosenbaum, Paul R. and Donald B. Rubin, "The Central Role of the Propensity Score in Observational Studies for Causal Effects," Biometrika, April 1983, 70 (1), 41-55.

Rudwick, Elliott M., "Negro Police Employment in the Urban South," Journal Negro Education, Spring 1961, 30 (2), 102-108.

, The Unequal Badge: Negro Policemen in the South, Atlanta: Southern Regional Council, 1962.

Schlei, Barbara Lindemann and Paul Grossman, Employment Discrimination Law, Washington, D.C.: Bureau of National Affairs, 1976.

Siskin, Bernard R. and David W. Griffin, "Analysis of Distributions by Rank, Race, and Gender: City of Chicago Police Department, 1987-1991," 1997. Philadelphia: Center for Forensic Economic Studies.

Smith, James P. and Finis Welch, "Black Economic Progress After Myrdal," Journal of Economic Literature, June 1989, 27 (2), 519-564.

Southern Regional Council, Southern Regional Council Papers, 1944-1968, Ann Arbor: University Microfilms International, 2000.

_

Spilerman, Seymour, "The Causes of Racial Disturbances: A Comparison of Alternative Explanations," American Sociological Review, August 1970, 35 (4), 627-649.

U.S. Department of Justice, "Employment Litigation Section Complaints Filed Involving Police of Fire Departments as of July 31, 2001," 2001. Unpublished manuscript. U.S. Department of Justice, Civil Rights Division, Employment Section.

Wallace, Phyllis A., Equal Employment Opportunity and the ATET Case, Cambridge: MIT Press, 1976. 


\section{Figure 1. The Chicago Experience}

\section{A. Black Employment Share and Black Hiring Share}

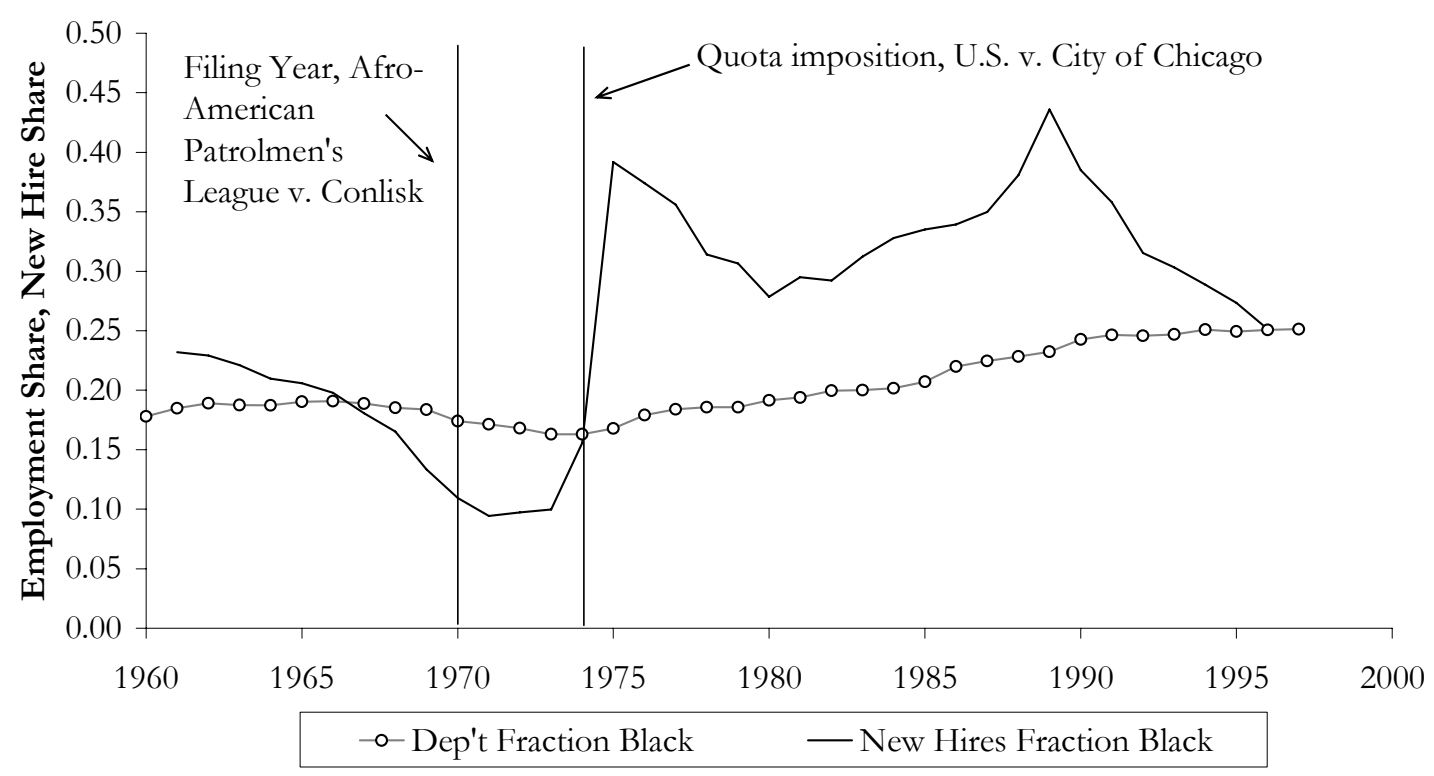

B. Production of Crime Control: Aggregate Inputs and Outputs

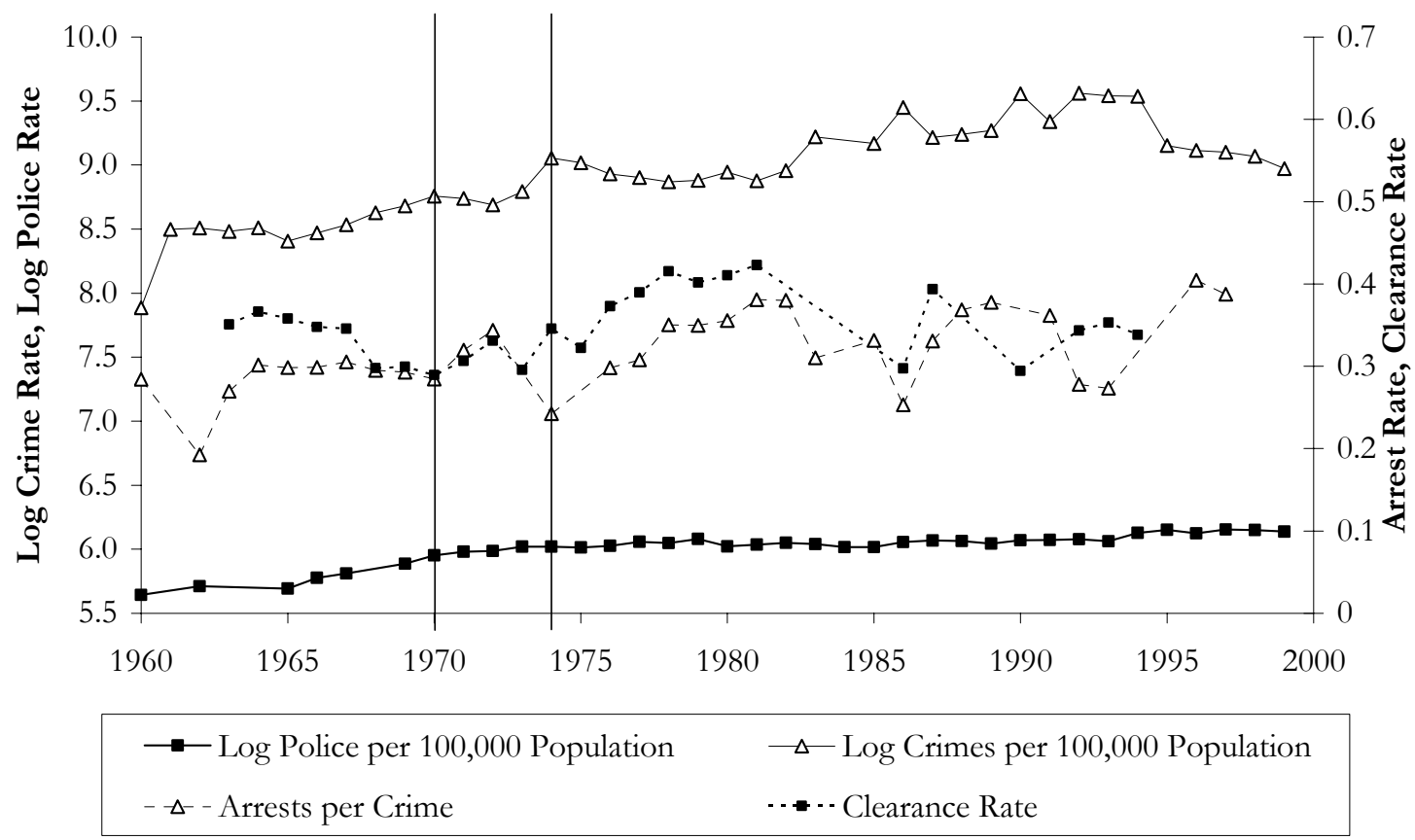




\section{Figure 1. The Chicago Experience (cont.)}

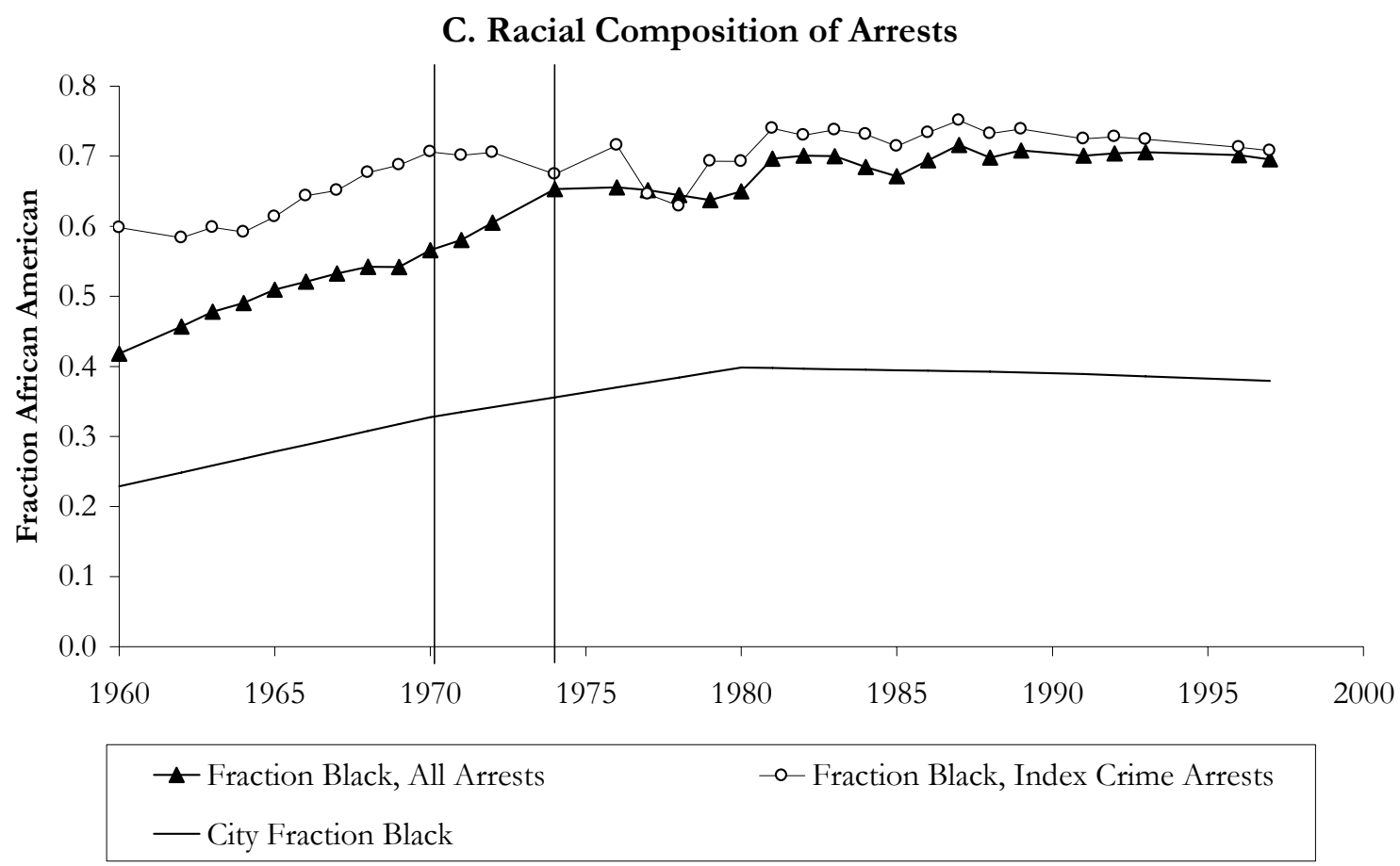


Figure 2. Map of Cities by Litigation Status

A. Unlitigated Cities

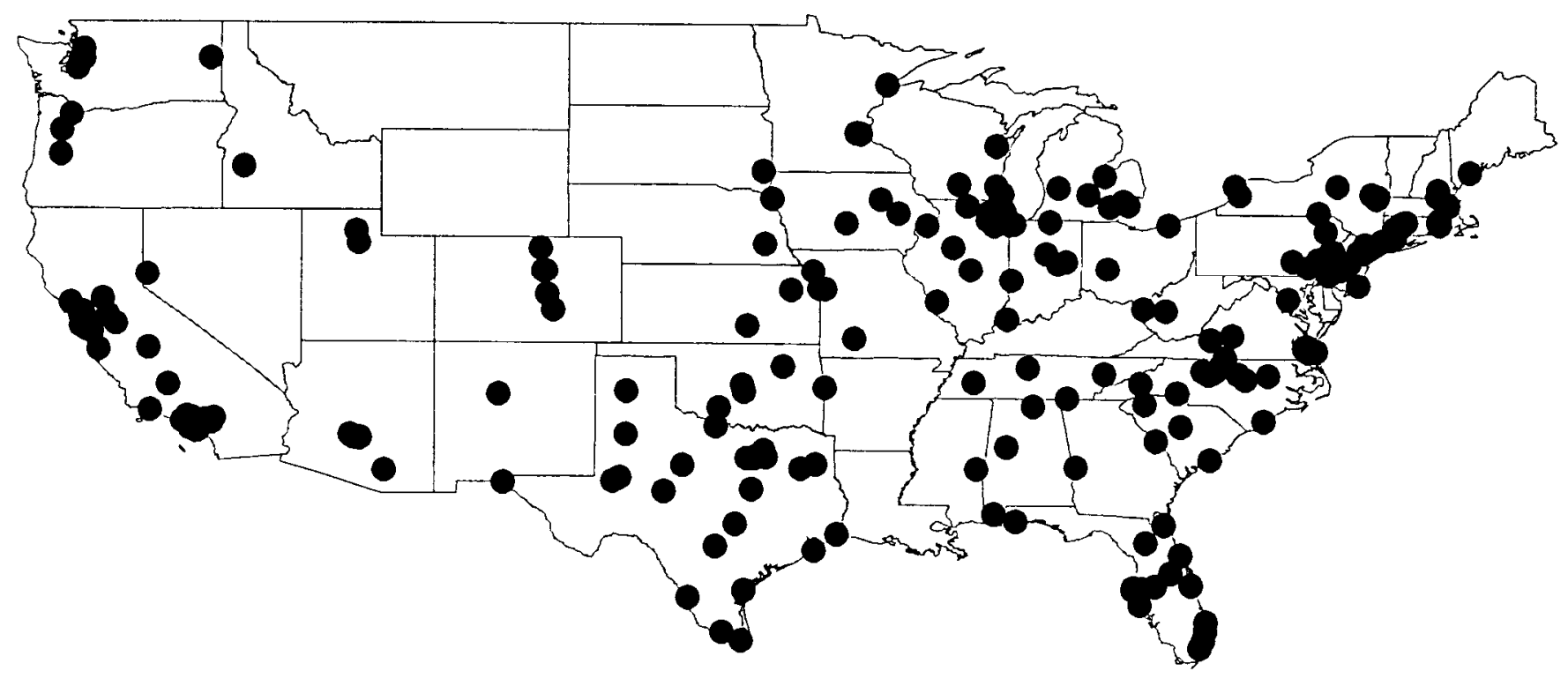

B. Litigated Cities

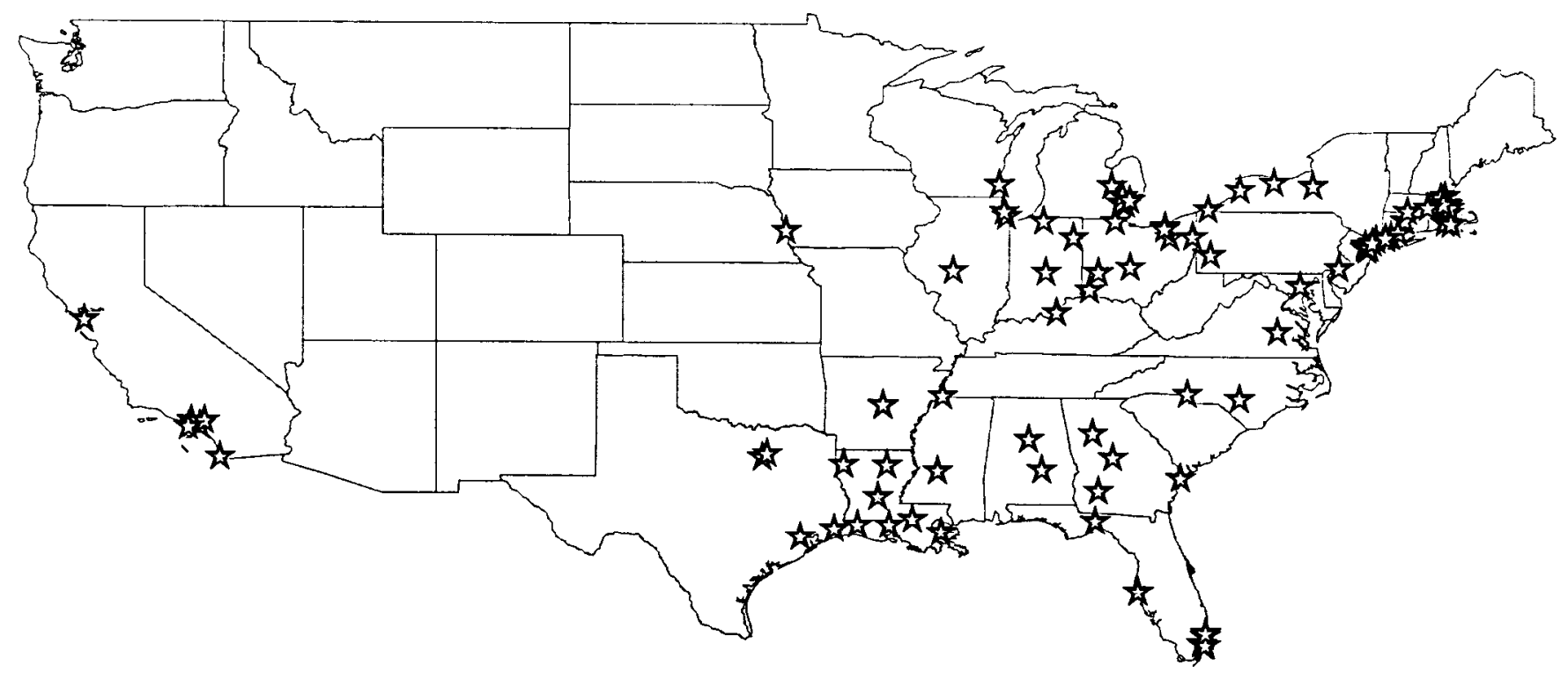




\section{Figure 3. Representation Gap by Litigation Status}

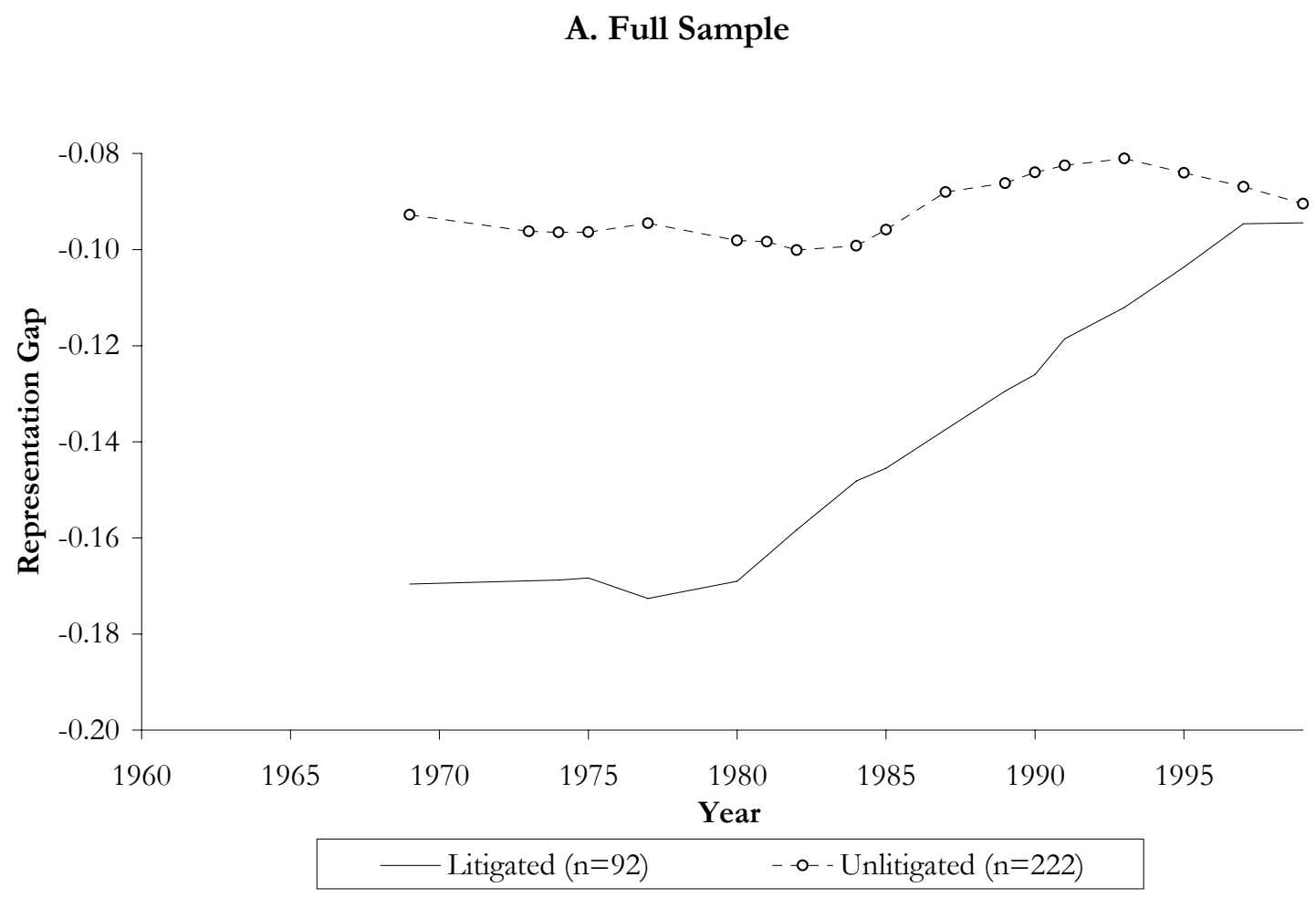

\section{B. Long Sample}

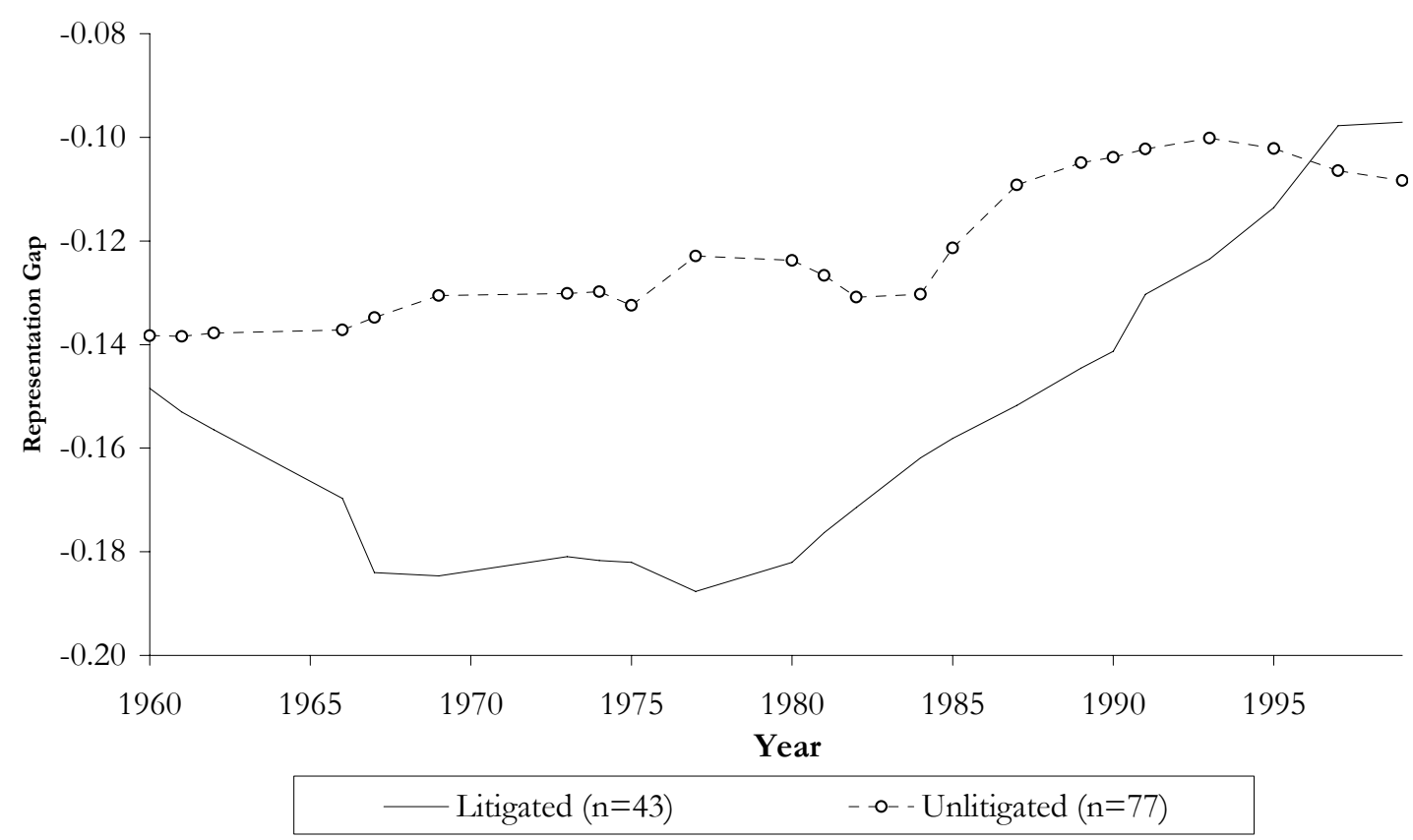

Note: Figure gives time series of the difference between police department black employment share and city fraction African American ("representation gap"), separately by litigation status, for two samples. See text for details. 
Figure 4. Histograms of Litigation Filing Dates

A. Unweighted

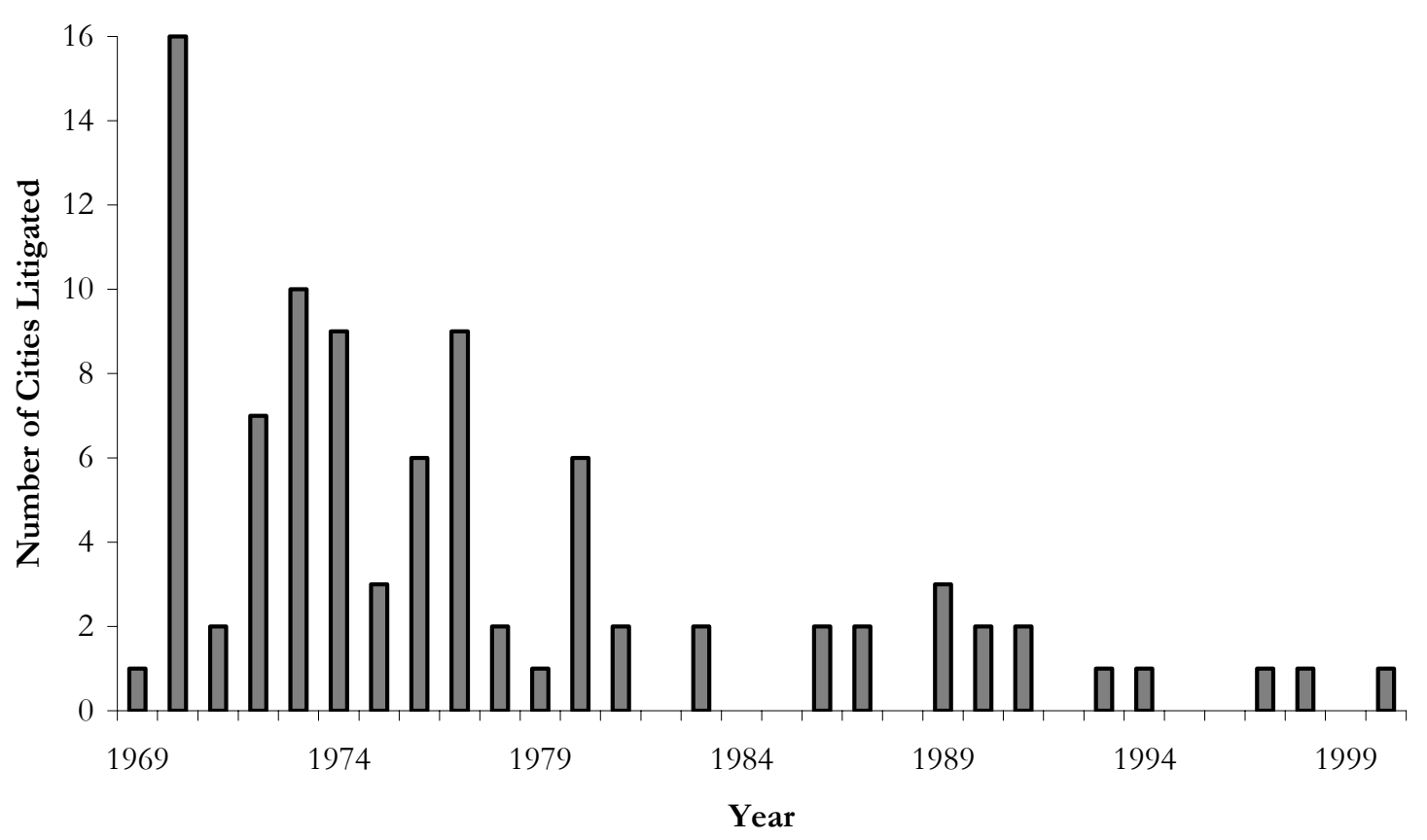

B. Weighted by 1970 City Population

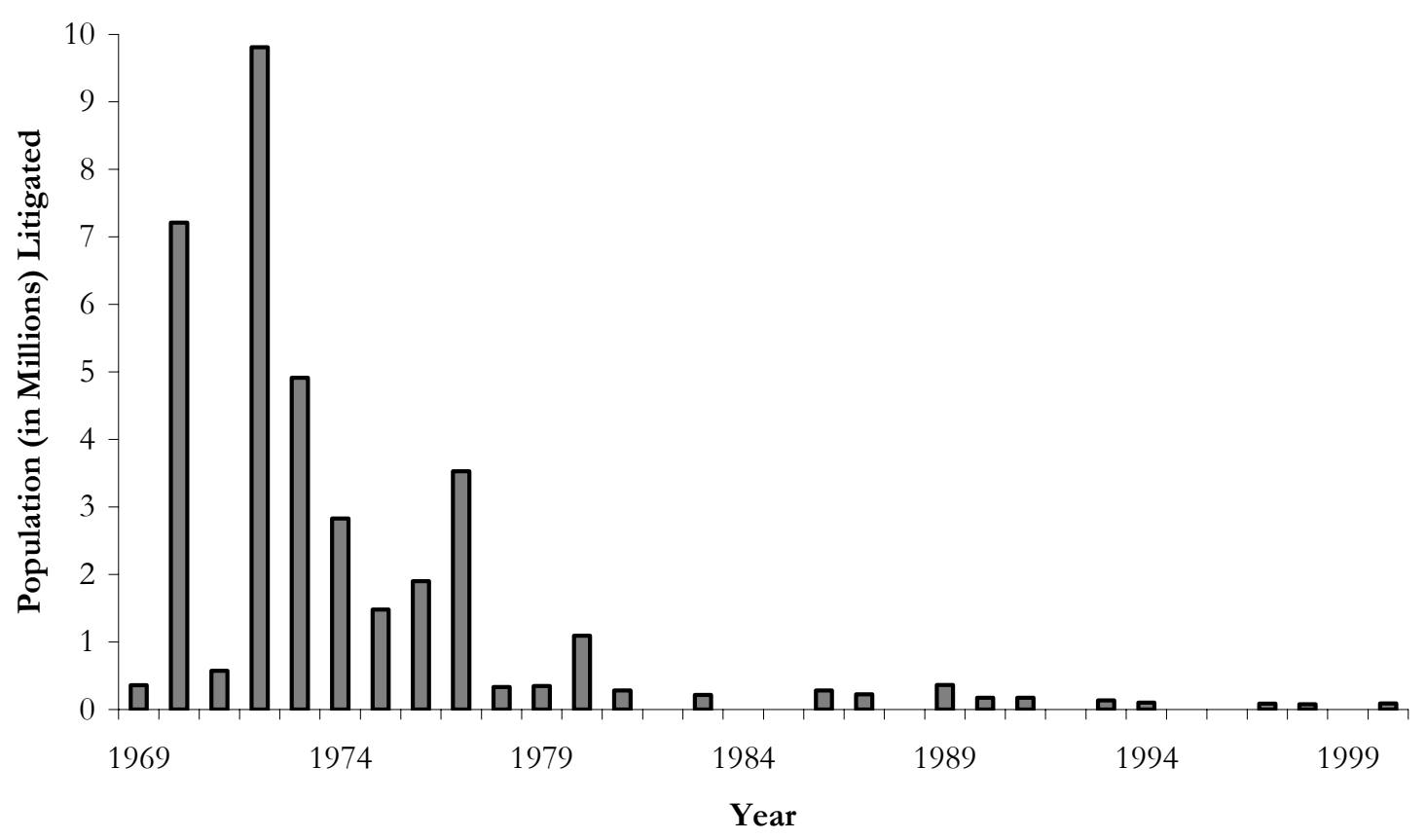




\section{Figure 5. Event Study Estimates of the Impact of Litigation on the Representation Gap}

\section{A. Full Sample}

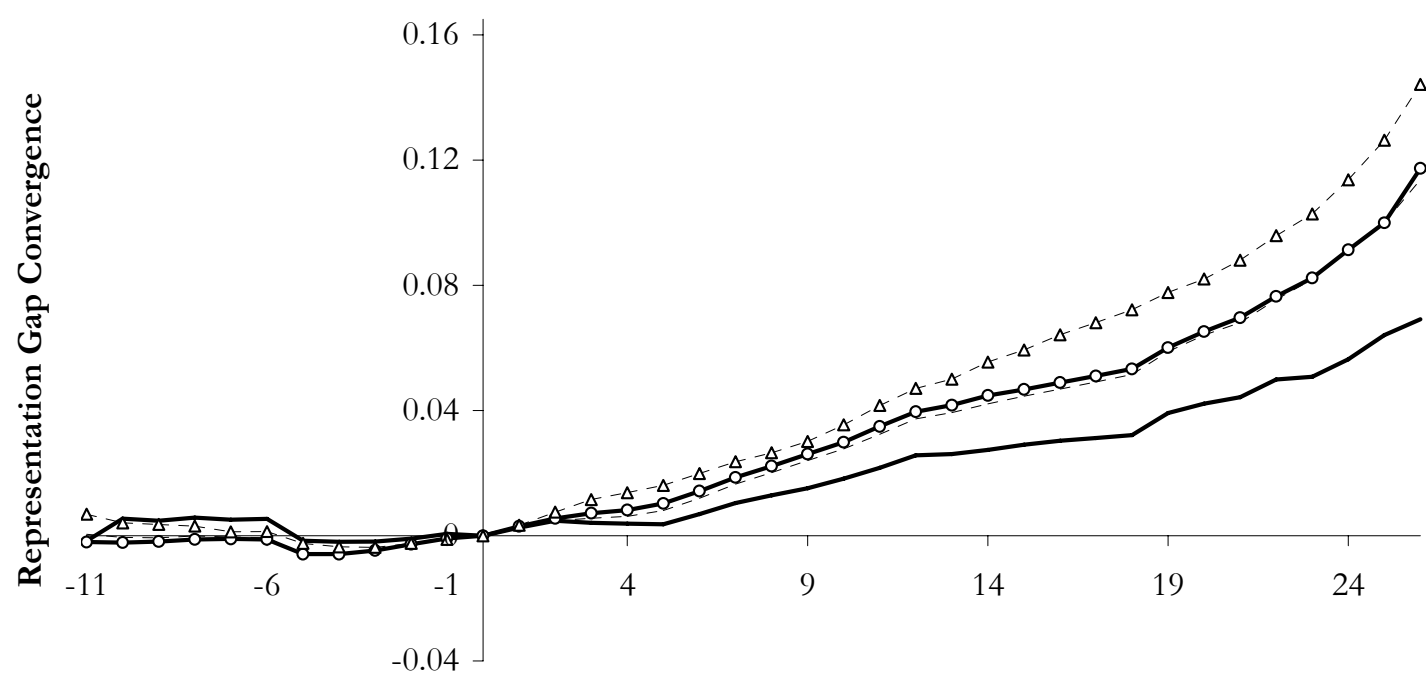

Years Since Litigation Filing Date

- Model 1: Year Effects Only $\quad---$ Model 2: Region by Year Effects
$\longrightarrow$ - Model 3: Division by Year Effects $-{ }_{-}^{-}-$Model 4: State by Year Effects

\section{B. Long Sample}

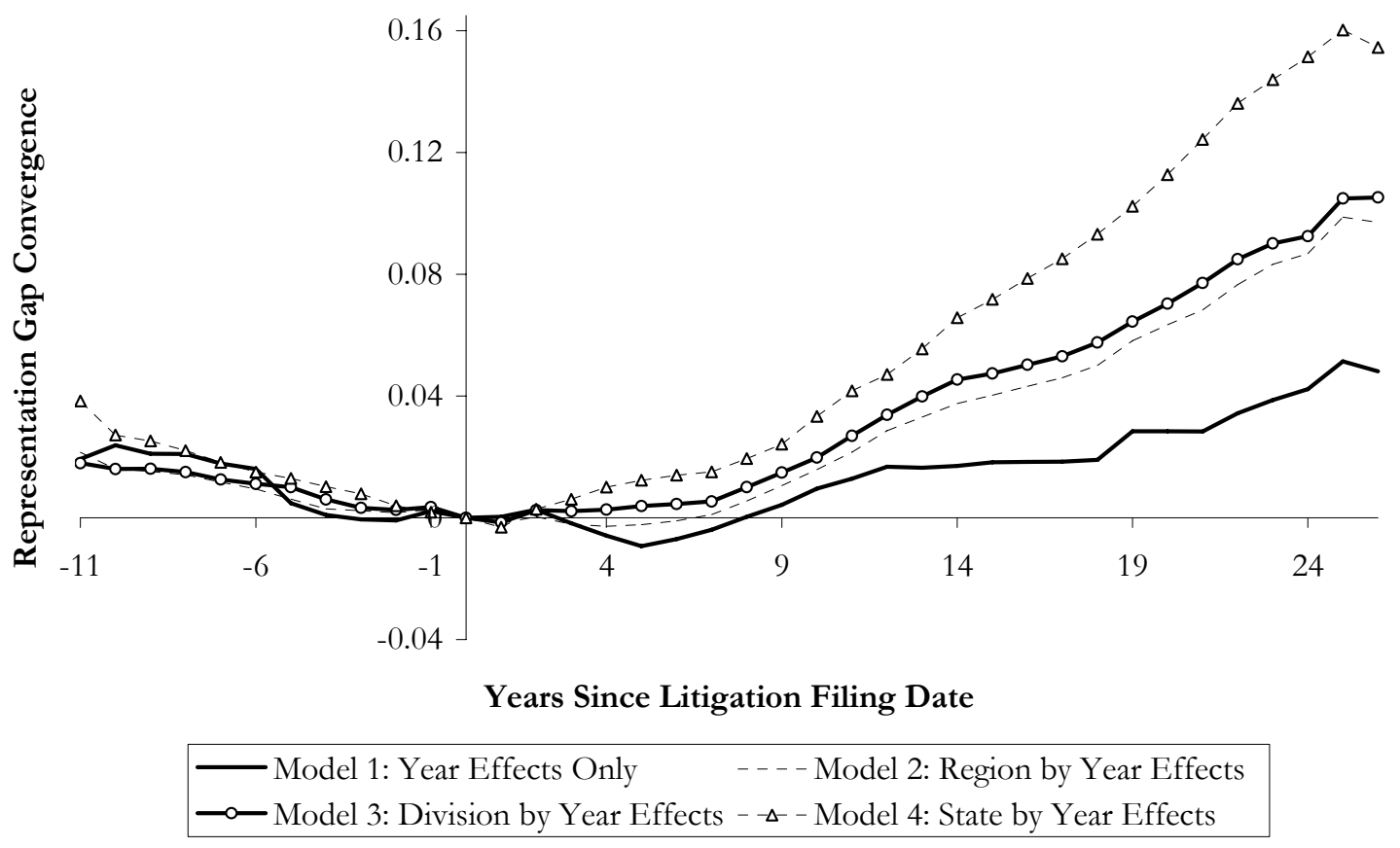




\section{Figure 6. A Direct Test of the Litigation Threat Effect Hypothesis}

\section{A. Unlitigated in Full Sample}

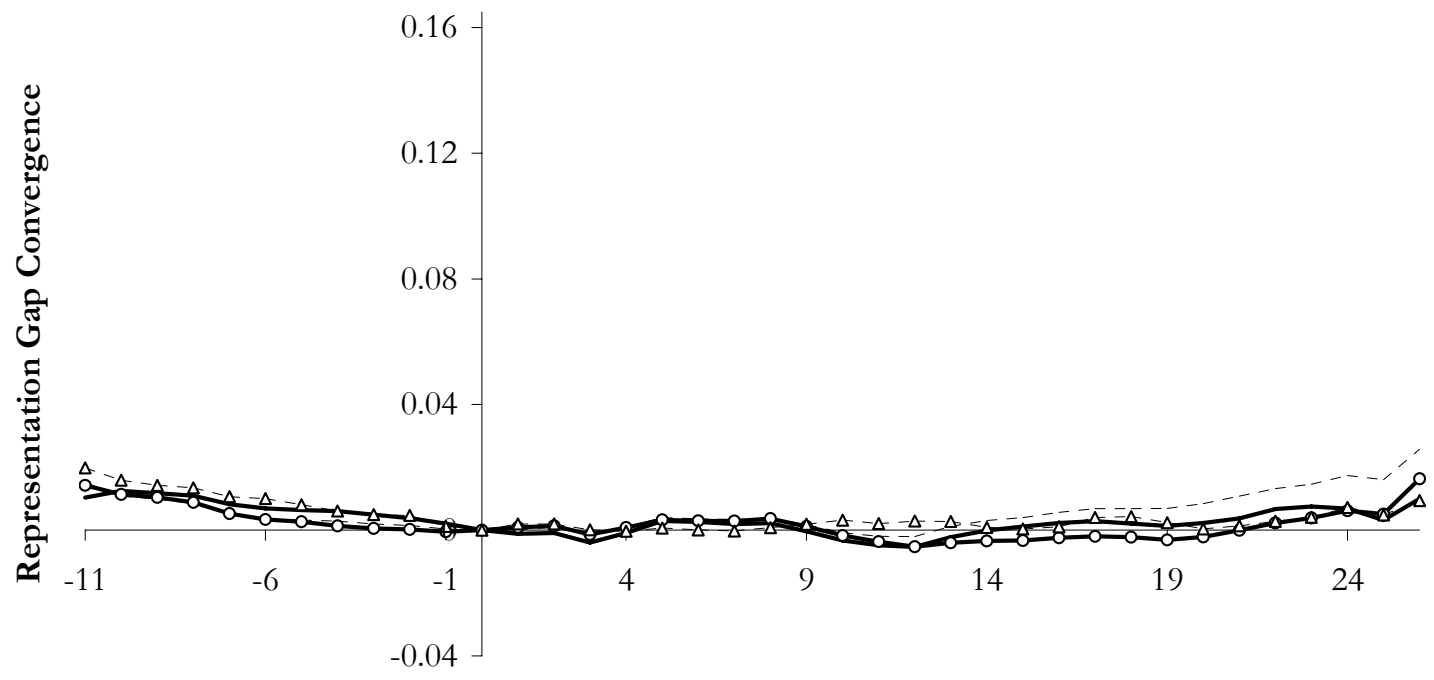

Years Since Neighbor's Litigation Filing Date

— Model 1: Year Effects Only _ - - - Model 2: Region by Year Effects

$\longrightarrow$ - Model 3: Division by Year Effects - -- Model 4: State by Year Effects

\section{B. Unlitigated in Long Sample}

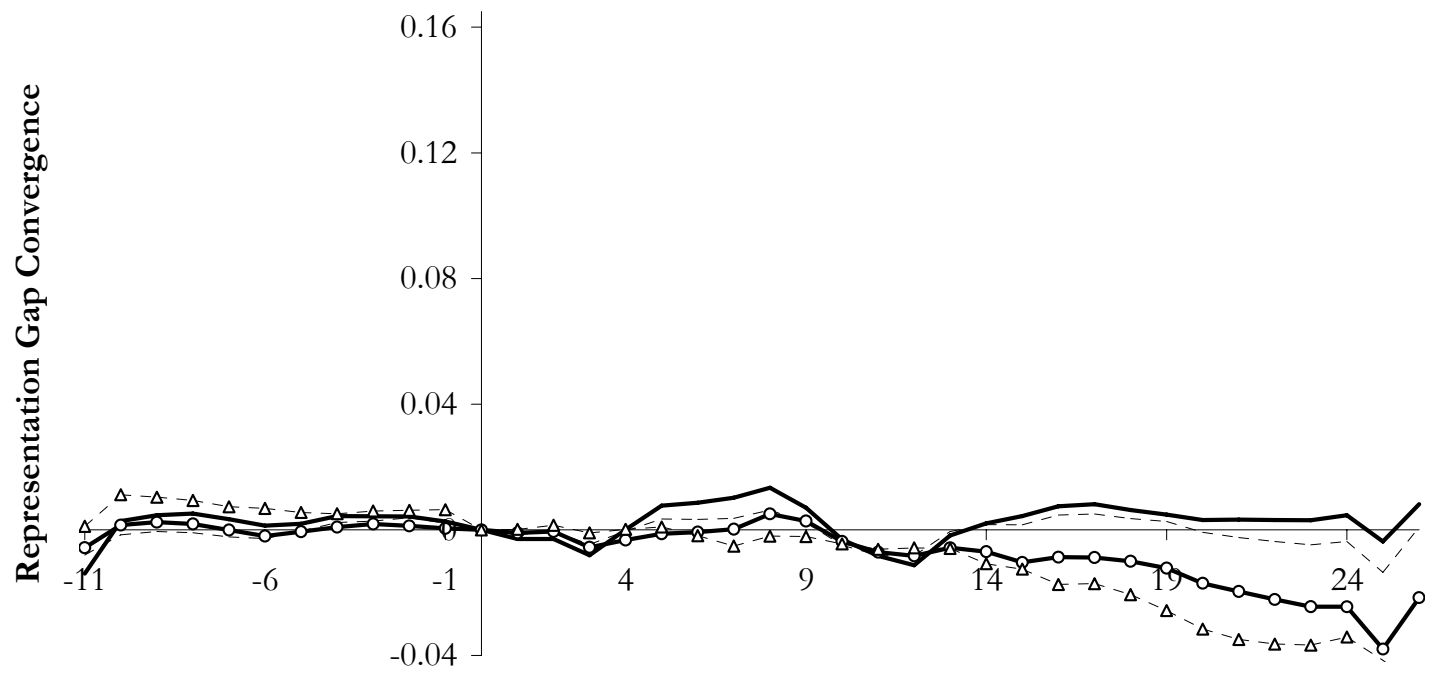

Years Since Neighbor's Litigation Filing Date

— Model 1: Year Effects Only _ - - - Model 2: Region by Year Effects

$\longrightarrow$ - Model 3: Division by Year Effects - -- -Model 4: State by Year Effects 
Figure 7. Police Performance Measures, by Litigation Status

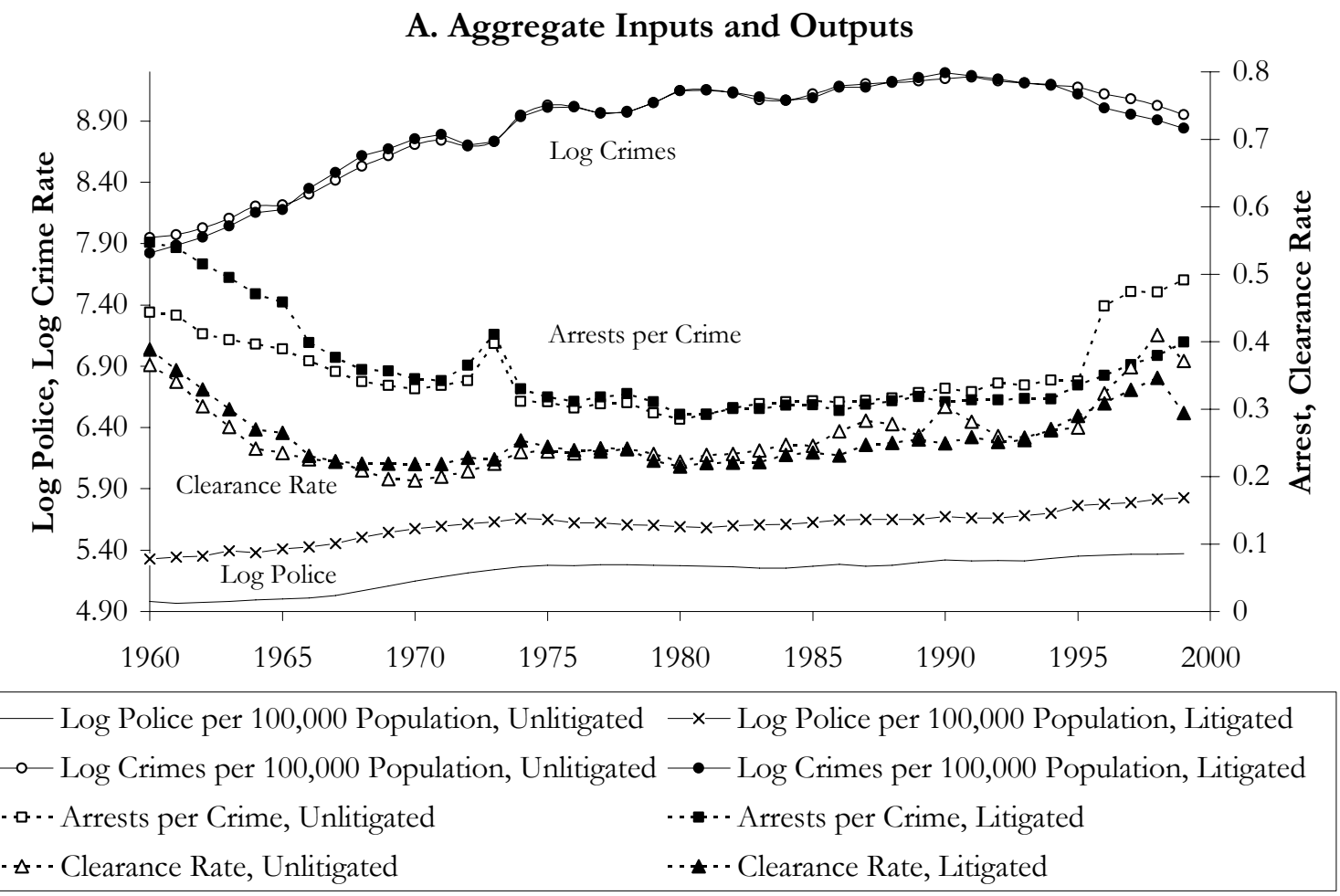

Note: Arrests per crime shifted by 10 percentage points for viewing purposes.

\section{B. Racial Composition of Arrests}

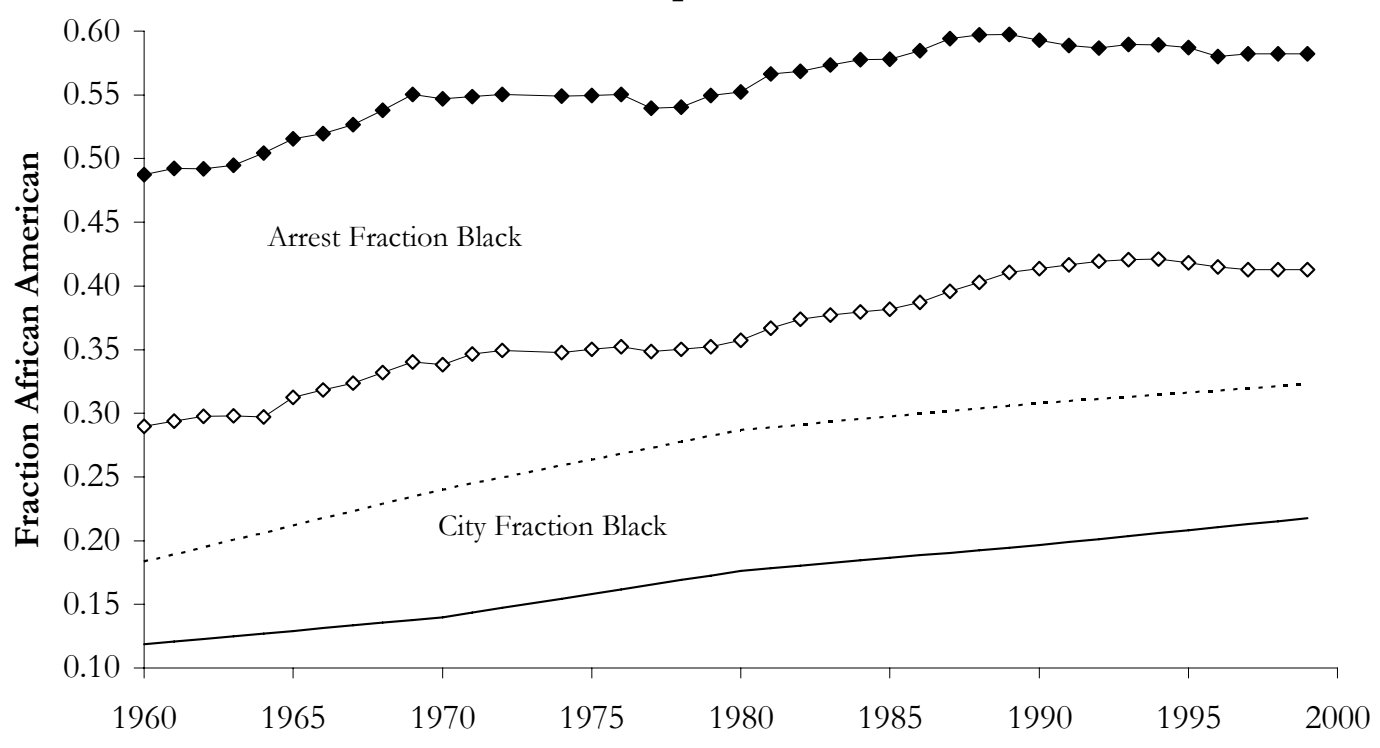

City Fraction Black, Unlitigated $\quad$...... City Fraction Black, Litigated

$\multimap$ Fraction Black, Index Arrests, Unlitigated $\bullet$ Fraction Black, Index Arrests, Litigated 


\section{Figure 8. Event Study Estimates of the Impact of Litigation on Police Performance}

A. Log Crime per 100,000 Population

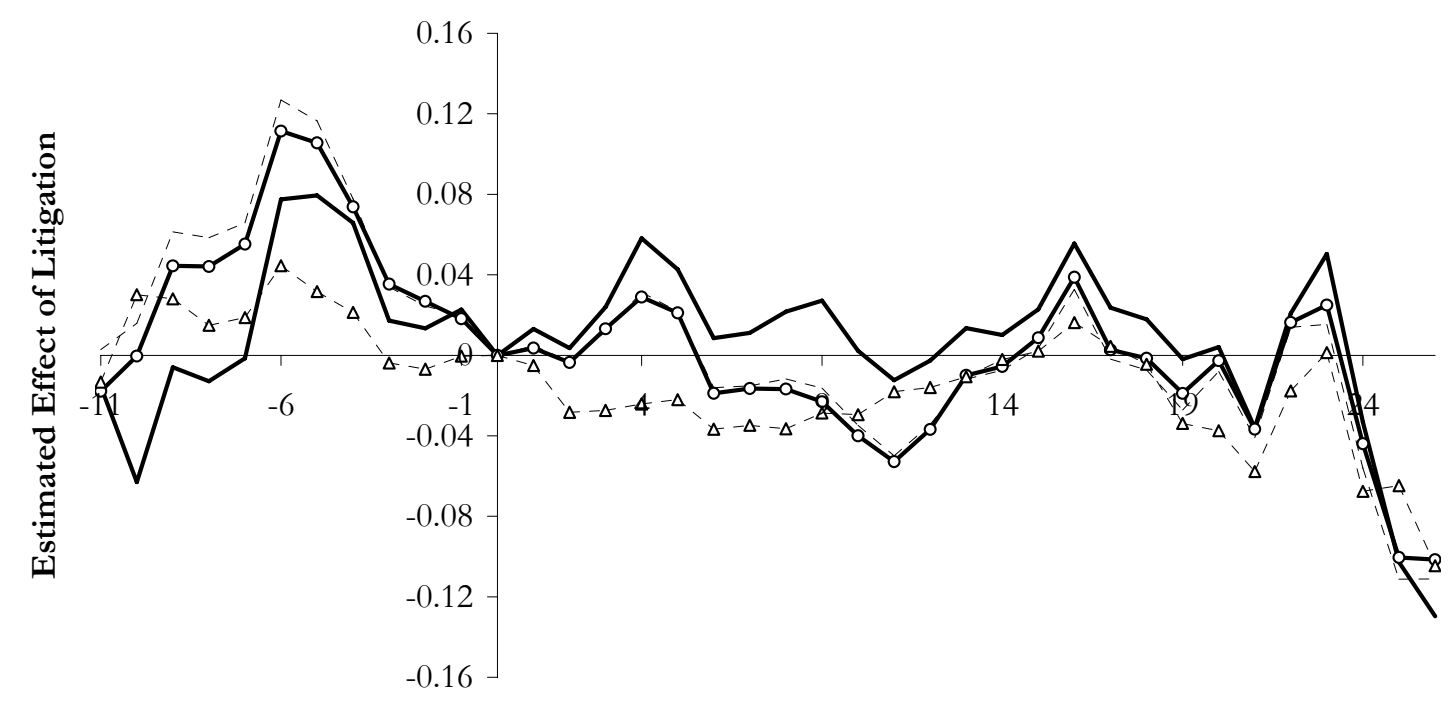

Years Since Litigation Filing Date

— Model 1: Year Effects Only _ - - - Model 2: Region by Year Effects

$\longrightarrow$ Model 3: Division by Year Effects - -- Model 4: State by Year Effects

\section{B. Clearance Rates}

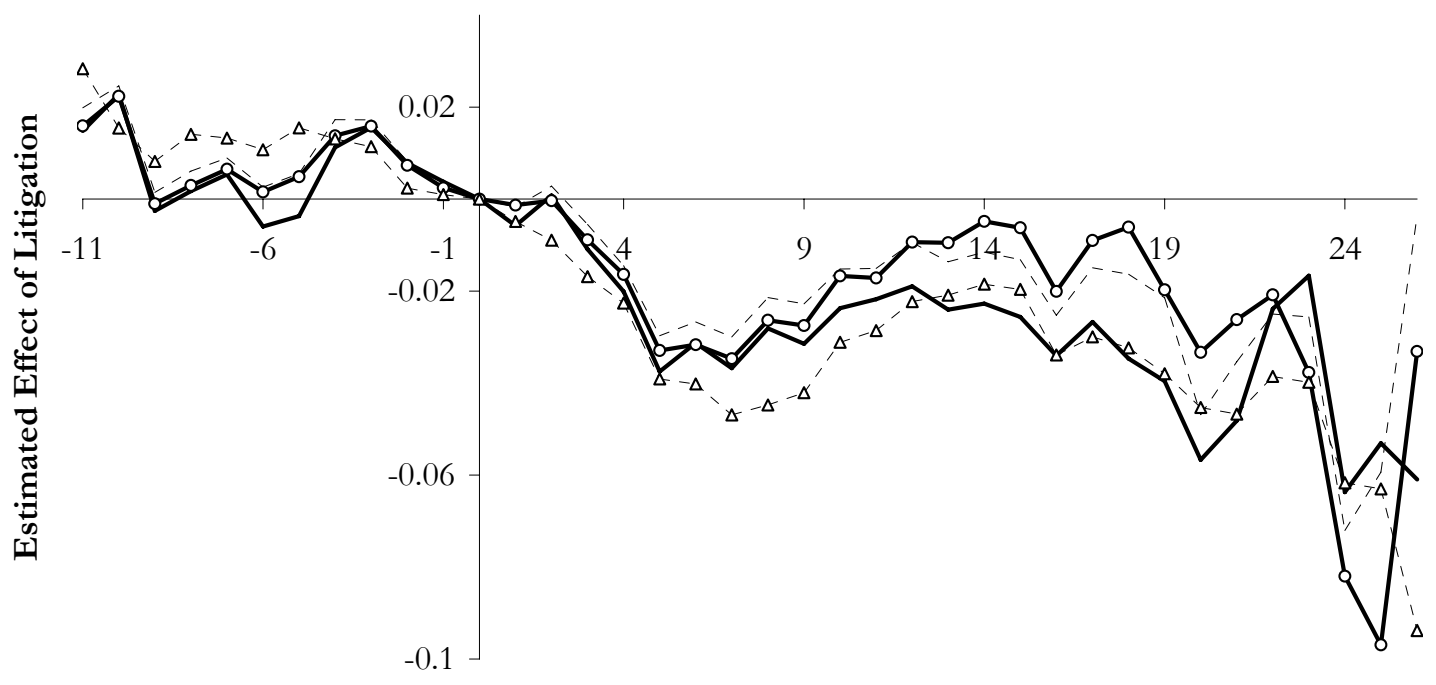

Years Since Litigation Filing Date 
Figure 8. Event Study Estimates of the Impact of Litigation on Police Performance (cont.)

C. Fraction Black, Index Crime Arrests

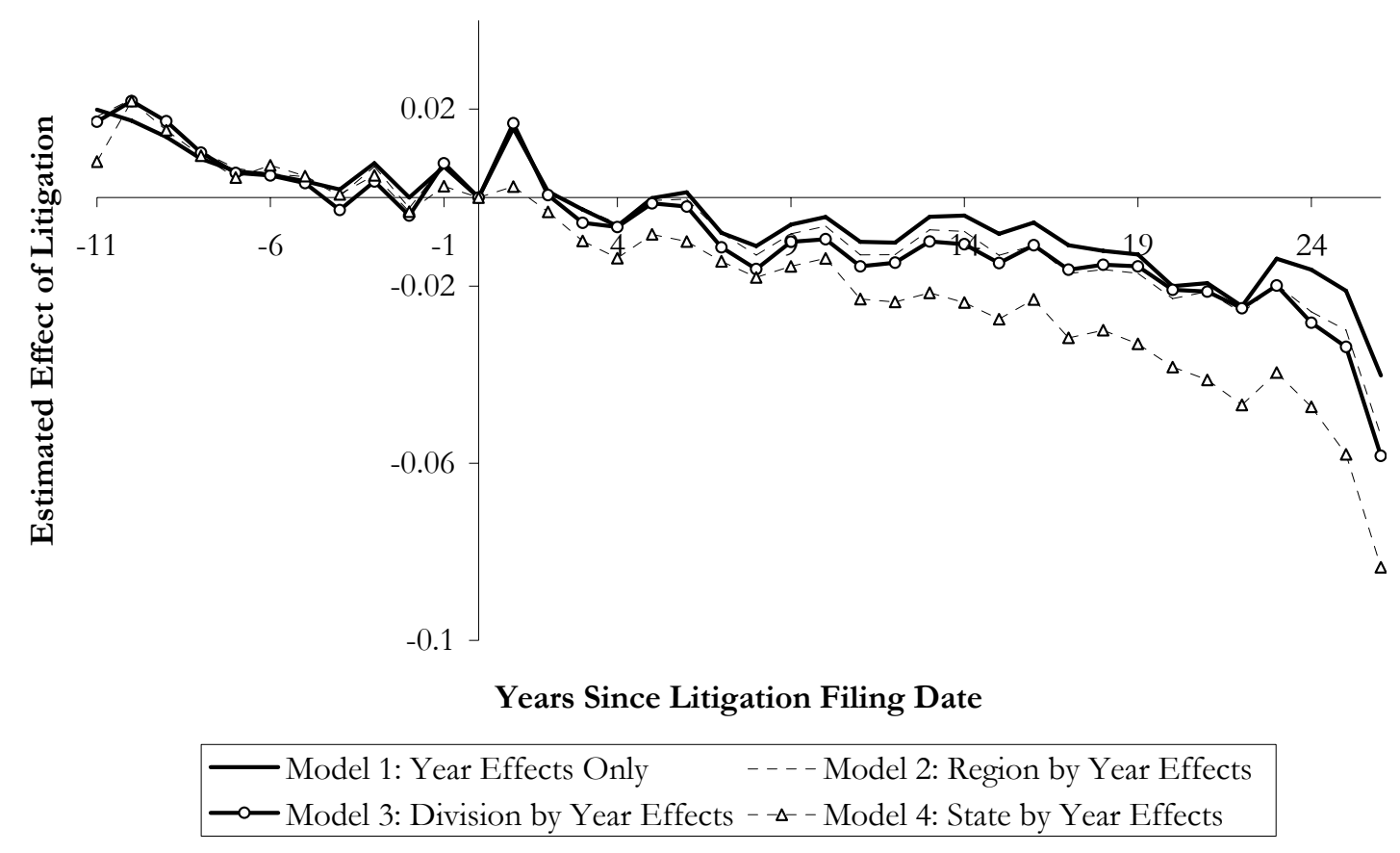




\section{Figure 9. Entrance Exam Score Distributions by Race, NYCPD}

\section{A. 1979 Exam}

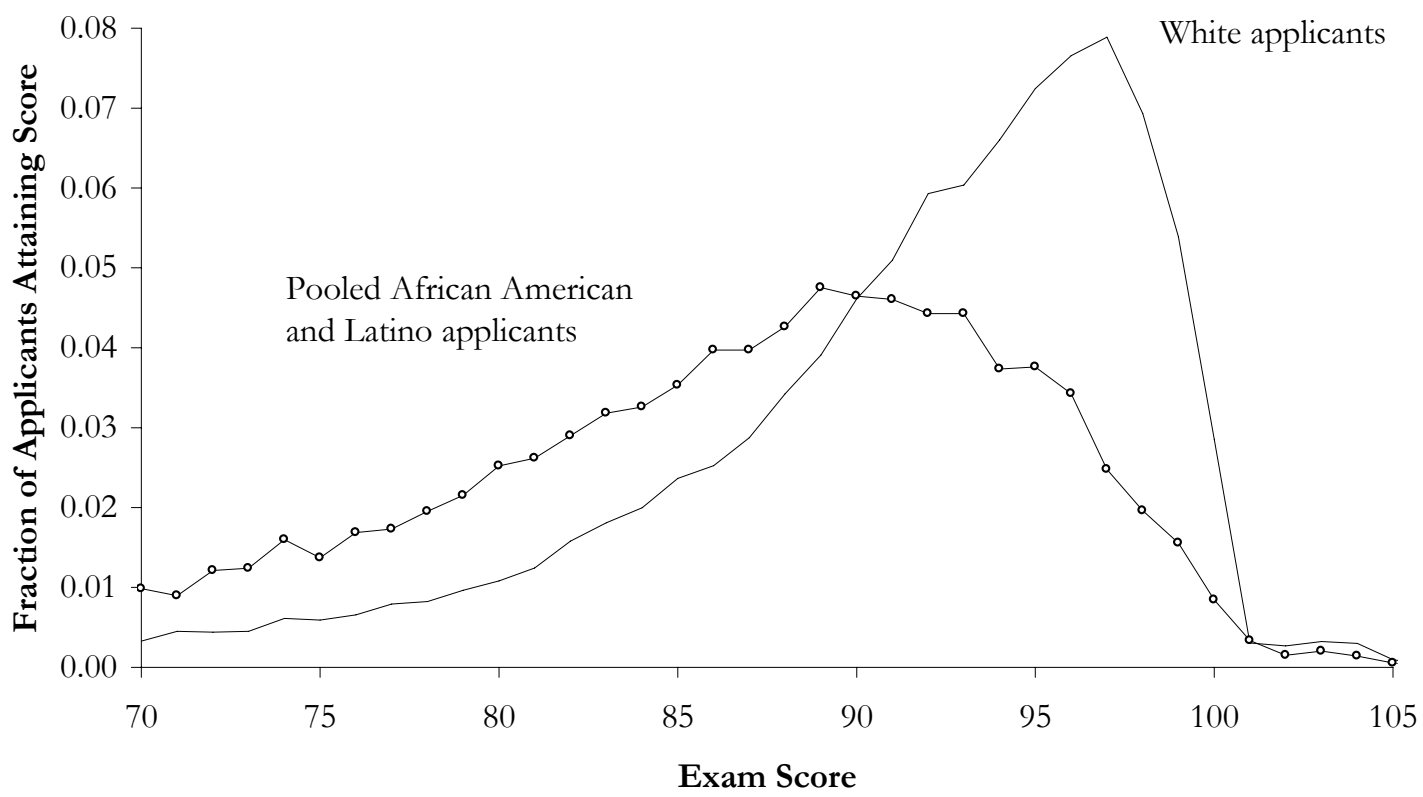

\section{B. 1998-1999 Exams}

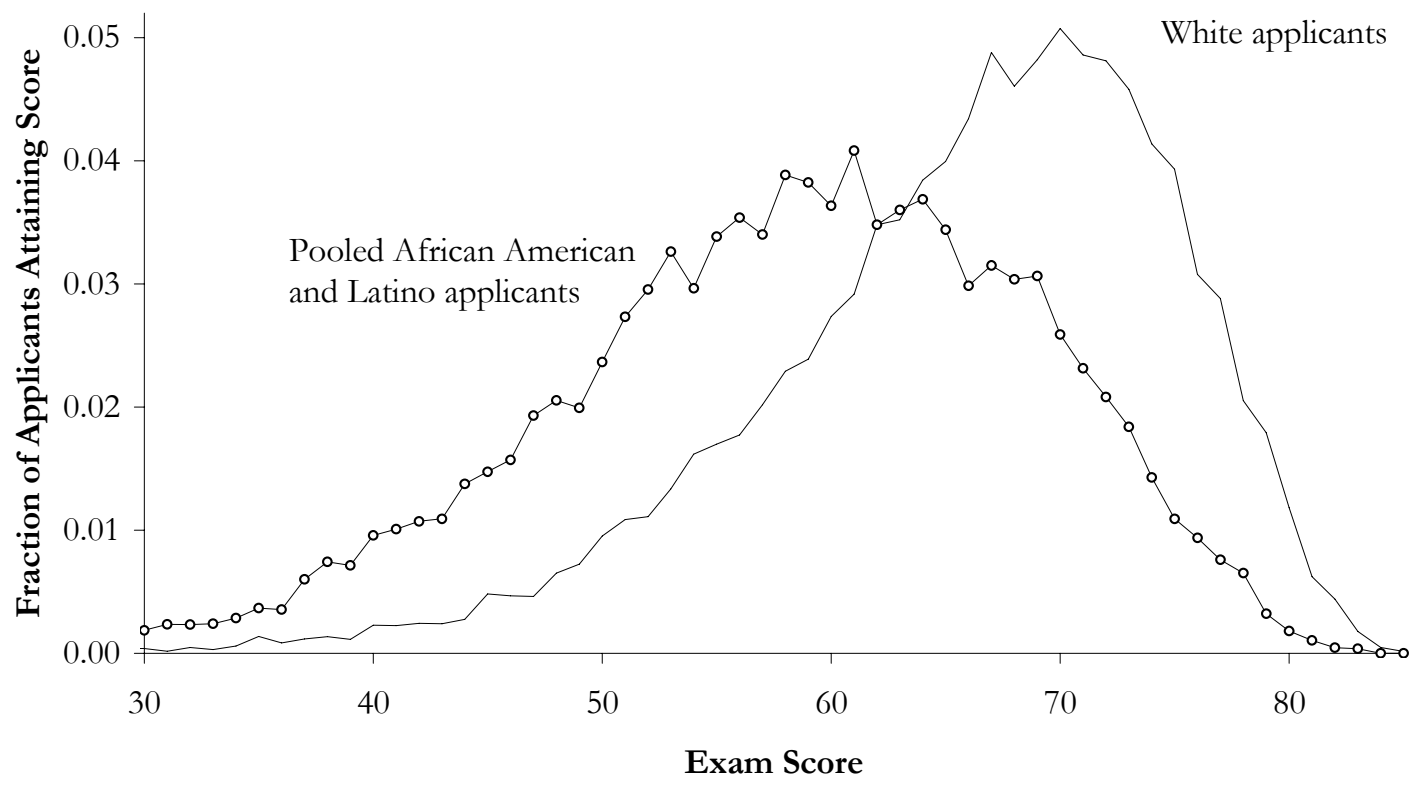


Table 1. Means and Standard Deviations of Key Variables by Litigation Status

Full Sample

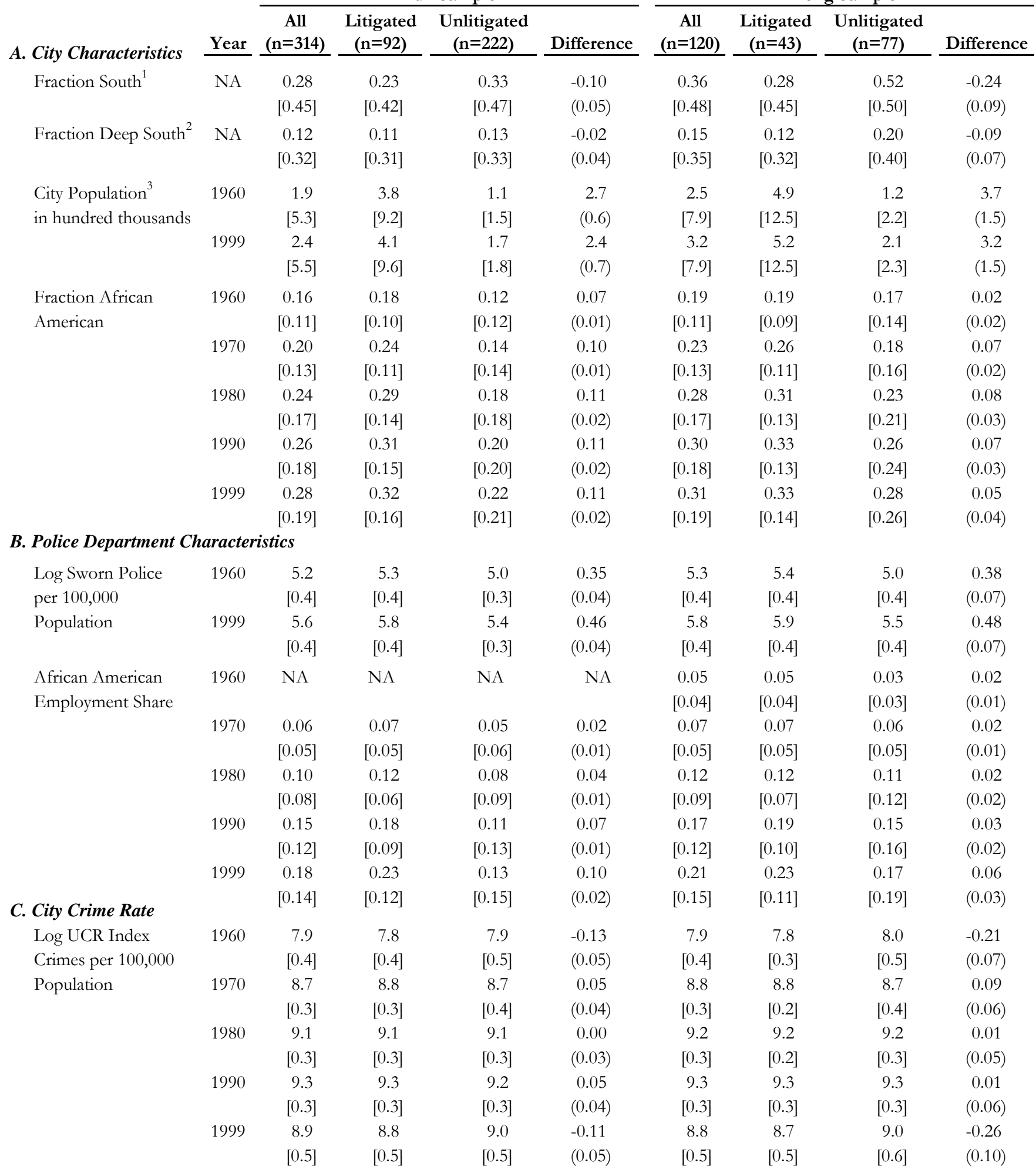

Notes: Standard deviations in brackets; standard errors in parentheses. Unless otherwise noted, all statistics are weighted by 1970 city population. ${ }^{1}$ South as defined by the Census Bureau. ${ }^{2}$ Deep South is defined as Alabama, Mississippi, Louisiana, Arkansas, Tennessee, Georgia, South Carolina, North Carolina, and Virginia. ${ }^{3}$ Equally weighted. 
Table 2. Means and Standard Deviations of Key Variables by Litigation Timing

\begin{tabular}{|c|c|c|c|c|c|c|}
\hline & Year & $\begin{array}{c}\text { Litigated } \\
1969-71 \\
(\mathrm{n}=19) \\
\end{array}$ & $\begin{array}{c}\text { Litigated } \\
1972-73 \\
(\mathrm{n}=17) \\
\end{array}$ & $\begin{array}{c}\text { Litigated } \\
1974-76 \\
(\mathrm{n}=18) \\
\end{array}$ & $\begin{array}{c}\text { Litigated } \\
1977-80 \\
(\mathrm{n}=18) \\
\end{array}$ & $\begin{array}{c}\text { Litigated } \\
1981-2000 \\
(n=20) \\
\end{array}$ \\
\hline \multicolumn{7}{|l|}{ A. City Characteristics } \\
\hline Fraction South & NA & 0.07 & 0.24 & 0.50 & 0.15 & 0.23 \\
\hline Fraction Deep South & NA & 0.03 & 0.10 & 0.25 & 0.12 & 0.06 \\
\hline \multirow{4}{*}{$\begin{array}{l}\text { City Population } \\
\text { in hundred thousands }\end{array}$} & 1960 & 4.4 & 8.5 & 3.1 & 2.7 & 0.9 \\
\hline & & {$[8.8]$} & [18.1] & {$[2.4]$} & {$[5.6]$} & {$[0.5]$} \\
\hline & 1999 & 4.0 & 8.5 & 3.7 & 3.4 & 1.2 \\
\hline & & {$[7.0]$} & [18.8] & {$[3.6]$} & {$[8.4]$} & {$[0.5]$} \\
\hline \multirow{10}{*}{$\begin{array}{l}\text { Fraction African } \\
\text { American }\end{array}$} & 1960 & 0.20 & 0.19 & 0.21 & 0.15 & 0.08 \\
\hline & & {$[0.09]$} & {$[0.09]$} & {$[0.12]$} & {$[0.08]$} & {$[0.10]$} \\
\hline & 1970 & 0.27 & 0.27 & 0.23 & 0.19 & 0.12 \\
\hline & & {$[0.11]$} & {$[0.11]$} & {$[0.11]$} & {$[0.07]$} & {$[0.13]$} \\
\hline & 1980 & 0.32 & 0.32 & 0.29 & 0.20 & 0.15 \\
\hline & & {$[0.13]$} & {$[0.13]$} & {$[0.13]$} & {$[0.09]$} & {$[0.16]$} \\
\hline & 1990 & 0.33 & 0.35 & 0.32 & 0.20 & 0.16 \\
\hline & & {$[0.12]$} & {$[0.13]$} & {$[0.15]$} & {$[0.11]$} & {$[0.17]$} \\
\hline & 1999 & 0.33 & 0.36 & 0.36 & 0.21 & 0.19 \\
\hline & & {$[0.12]$} & {$[0.14]$} & {$[0.18]$} & {$[0.14]$} & {$[0.18]$} \\
\hline \multicolumn{7}{|c|}{ B. Police Department Characteristics } \\
\hline \multirow{4}{*}{$\begin{array}{l}\text { Log Sworn Police } \\
\text { per } 100,000 \text { Population }\end{array}$} & 1960 & 5.6 & 5.5 & 5.1 & 5.1 & 4.9 \\
\hline & & {$[0.2]$} & {$[0.4]$} & {$[0.3]$} & {$[0.2]$} & {$[0.4]$} \\
\hline & 1999 & 6.0 & 6.0 & 5.5 & 5.6 & 5.4 \\
\hline & & {$[0.3]$} & {$[0.3]$} & {$[0.2]$} & {$[0.2]$} & {$[0.4]$} \\
\hline \multirow{10}{*}{$\begin{array}{l}\text { African American } \\
\text { Employment Share }\end{array}$} & 1960 & $0.08^{1}$ & $0.04^{1}$ & $0.04^{1}$ & NA & NA \\
\hline & & {$[0.05]$} & {$[0.01]$} & {$[0.04]$} & & \\
\hline & 1970 & 0.12 & 0.06 & 0.05 & 0.04 & 0.04 \\
\hline & & {$[0.07]$} & {$[0.03]$} & {$[0.03]$} & {$[0.02]$} & {$[0.05]$} \\
\hline & 1980 & 0.16 & 0.12 & 0.10 & 0.09 & 0.05 \\
\hline & & {$[0.06]$} & {$[0.06]$} & {$[0.05]$} & {$[0.03]$} & {$[0.05]$} \\
\hline & 1990 & 0.21 & 0.19 & 0.19 & 0.15 & 0.08 \\
\hline & & {$[0.07]$} & {$[0.10]$} & {$[0.10]$} & {$[0.05]$} & {$[0.08]$} \\
\hline & 1999 & 0.26 & 0.25 & 0.24 & 0.16 & 0.09 \\
\hline & & {$[0.09]$} & {$[0.11]$} & {$[0.15]$} & {$[0.06]$} & {$[0.08]$} \\
\hline \multicolumn{7}{|l|}{ C. City Crime Rate } \\
\hline \multirow{10}{*}{$\begin{array}{l}\text { Log UCR Index Crimes } \\
\text { per } 100,000 \text { Population }\end{array}$} & 1960 & 7.8 & 7.8 & 7.8 & 8.1 & 7.8 \\
\hline & & {$[0.3]$} & {$[0.2]$} & {$[0.2]$} & {$[0.5]$} & {$[0.5]$} \\
\hline & 1970 & 8.6 & 8.9 & 8.7 & 8.8 & 8.6 \\
\hline & & {$[0.4]$} & {$[0.2]$} & {$[0.2]$} & {$[0.2]$} & {$[0.5]$} \\
\hline & 1980 & 9.0 & 9.2 & 9.1 & 9.2 & 9.1 \\
\hline & & {$[0.3]$} & {$[0.1]$} & {$[0.3]$} & {$[0.2]$} & {$[0.5]$} \\
\hline & 1990 & 9.3 & 9.3 & 9.3 & 9.2 & 9.2 \\
\hline & & {$[0.4]$} & {$[0.2]$} & {$[0.4]$} & {$[0.2]$} & {$[0.5]$} \\
\hline & 1999 & 9.0 & 8.7 & 9.1 & 8.8 & 8.8 \\
\hline & & {$[0.3]$} & {$[0.5]$} & {$[0.3]$} & {$[0.3]$} & {$[0.6]$} \\
\hline
\end{tabular}

Notes: Standard deviations in brackets. Estimates presented are based on the full sample only, unless otherwise noted. ${ }^{1}$ Estimates for 1969-71, 1972-73, and 1974-76 taken from the 11, 9, and 8 respective cities in the long sample with litigation dates in the given categories. Estimates for other litigation date ranges omitted because long sample cities do not appear to be representative. 


\section{Table 3. Parametric Estimates of the Impact of Litigation on the Representation Gap}

\section{A. Full Sample Estimates}

\begin{tabular}{|c|c|c|c|c|}
\hline & & All 31 & Cities & \\
\hline & Model 1 & Model 2 & Model 3 & Model 4 \\
\hline & (1) & (2) & (3) & (4) \\
\hline $25 *$ Post- & 0.060 & 0.096 & 0.097 & 0.121 \\
\hline Litigation Trend & $(0.031)$ & $(0.022)$ & $(0.024)$ & $(0.018)$ \\
\hline & & Cities Ide & fying Mo & \\
\hline & Model 1 & Model 2 & Model 3 & Model 4 \\
\hline & (9) & (10) & (11) & (12) \\
\hline $25 *$ Post- & 0.055 & 0.101 & 0.101 & 0.121 \\
\hline Litigation Trend & $(0.033)$ & $(0.026)$ & $(0.027)$ & $(0.018)$ \\
\hline
\end{tabular}

\section{B. Long Sample Estimates}

All 120 Cities

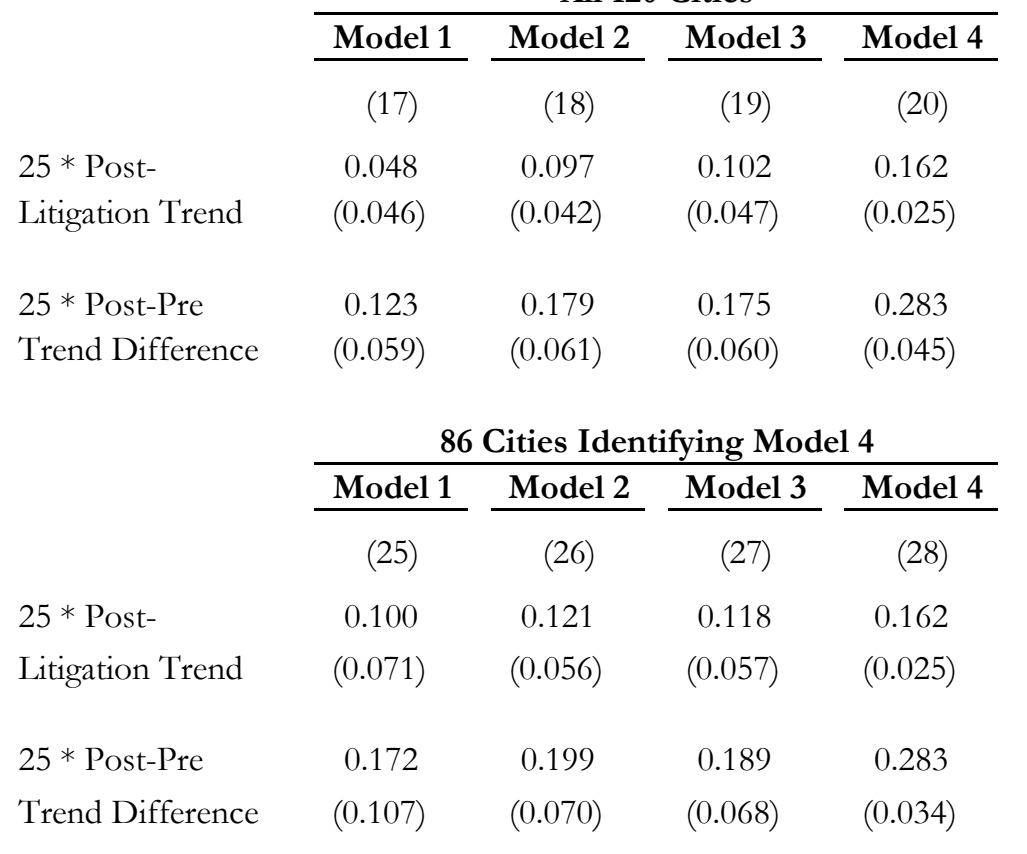

\begin{tabular}{|c|c|c|c|}
\hline \multicolumn{4}{|c|}{92 Litigated Cities Only } \\
\hline Model 1 & Model 2 & Model 3 & Model 4 \\
\hline$(5)$ & (6) & (7) & (8) \\
\hline 0.057 & 0.107 & 0.107 & 0.154 \\
\hline$(0.066)$ & $(0.046)$ & $(0.045)$ & $(0.032)$ \\
\hline
\end{tabular}

Reweighting the Unlitigated

\begin{tabular}{|c|c|c|c|}
\hline Model 1 & Model 2 & Model 3 & Model 4 \\
\hline (13) & (14) & (15) & (16) \\
\hline 0.033 & 0.073 & 0.072 & 0.113 \\
\hline (0.032) & $(0.028)$ & $(0.032)$ & $(0.022)$ \\
\hline
\end{tabular}

43 Litigated Cities Only

\begin{tabular}{|c|c|c|c|}
\hline Model 1 & Model 2 & Model 3 & Model 4 \\
\hline (21) & (22) & (23) & (24) \\
\hline 0.049 & 0.106 & 0.108 & 0.158 \\
\hline$(0.062)$ & $(0.052)$ & (0.054) & (0.035) \\
\hline 0.041 & 0.162 & 0.158 & 0.278 \\
\hline (0.091) & (0.055) & $(0.056)$ & $(0.040)$ \\
\hline
\end{tabular}

Reweighting the Unlitigated

\begin{tabular}{|c|c|c|c|}
\hline Model 1 & Model 2 & Model 3 & Model 4 \\
\hline (29) & $(30)$ & (31) & $(32)$ \\
\hline 0.036 & 0.094 & 0.095 & 0.156 \\
\hline$(0.046)$ & $(0.041)$ & $(0.046)$ & $(0.032)$ \\
\hline 0.134 & 0.183 & 0.173 & 0.289 \\
\hline$(0.069)$ & $(0.067)$ & $(0.063)$ & $(0.041)$ \\
\hline
\end{tabular}

Notes: Standard errors, clustered at the level of the city and adjusted for degrees of freedom, presented in parentheses. Panel A presents estimates of the annual gain (times 25) in representation gap in the years following litigation for four choices of specification, three subsets of the full sample, and two different weighting schemes. The four specifications correspond to those from Figure 5: year effects only, region-by-year effects, division-by-year effects, and state-by-year effects. Estimates in columns (13) to (16) are weighted by a factor that approximately equalizes in distribution the 1969 representation gap for litigated and unlitigated cities (see text for details). Panel B is organized identically, but is based on the 120 cities in the long sample. Panel B additionally reports the difference in post-litigation and pre-litigation annual gains in representation gap. 


\section{Table 4. Parametric Estimates of the Impact of Litigation on Police Performance}

Log Police per 100,000 Population

\begin{tabular}{llll}
\hline Model 1 & Model 2 & Model 3 & Model 4 \\
\end{tabular}

(1)

$25 *$ Post-

Litigation Trend

$25 *$ Post-Pre

Trend Difference

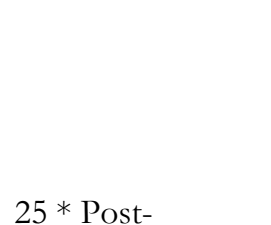

Litigation Trend

Trend Difference
$25 *$ Post-Pre

\section{Arrest Rate}

\begin{tabular}{|c|c|c|c|}
\hline Model 1 & Model 2 & Model 3 & Model 4 \\
\hline (9) & (10) & (11) & (12) \\
\hline-0.072 & -0.077 & -0.078 & -0.229 \\
\hline$(0.059)$ & $(0.059)$ & $(0.061)$ & $(0.151)$ \\
\hline 0.114 & 0.039 & 0.012 & -0.275 \\
\hline$(0.145)$ & $(0.097)$ & $(0.095)$ & $(0.211)$ \\
\hline
\end{tabular}

Fraction Black, All Arrests

\begin{tabular}{|c|c|c|c|}
\hline Model 1 & Model 2 & Model 3 & Model 4 \\
\hline
\end{tabular}

(18)

(19)

(20)

0.002

$-0.023$

(0.018)

(0.019)

$(0.023)$

(0.020)

0.004

$-0.004$

$-0.006$

$-0.041$

$(0.043)$

(0.038)

(0.038)

(0.039)
Log Crime per 100,000 Population \begin{tabular}{llll}
\hline Model 1 & Model 2 & Model 3 & Model 4 \\
\cline { 3 - 4 }
\end{tabular}

\author{
(5)
}

(6)

(7)

(8)

$\begin{array}{llll}-0.077 & -0.088 & -0.080 & -0.044 \\ (0.137) & (0.062) & (0.059) & (0.050) \\ & & & \\ -0.211 & -0.078 & -0.111 & -0.024 \\ (0.365) & (0.153) & (0.145) & (0.116)\end{array}$

\section{Clearance Rate}

\begin{tabular}{|c|c|c|c|}
\hline Model 1 & Model 2 & Model 3 & Model 4 \\
\hline (13) & (14) & (15) & $(16)$ \\
\hline-0.044 & -0.029 & -0.035 & -0.048 \\
\hline$(0.041)$ & $(0.038)$ & $(0.040)$ & $(0.032)$ \\
\hline-0.001 & 0.023 & 0.006 & 0.030 \\
\hline (0.058) & $(0.054)$ & $(0.058)$ & $(0.048)$ \\
\hline
\end{tabular}

Fraction Black, All Index Arrests \begin{tabular}{llll}
\hline Model 1 & Model 2 & Model 3 & Model 4 \\
\end{tabular}

(21) (22) (23) (24)

$25 *$ Post-Pre
Trend Difference

$-0.026$

$-0.033$

$-0.033$

$-0.054$

(0.020)

$(0.020)$

(0.018)

$(0.017)$

Notes: Standard errors, clustered at the level of the city, presented in parentheses. 


\section{Table 5. New York City Police Department Entrance Examination Scores by Race, 1968-1999}

\begin{tabular}{|c|c|c|c|}
\hline \multirow[b]{2}{*}{ Decile } & \multicolumn{3}{|c|}{ July 1968 Examination } \\
\hline & $\begin{array}{l}\text { Score } \\
\text { Range }\end{array}$ & $\begin{array}{c}\text { White } \\
\text { Fraction }\end{array}$ & $\begin{array}{c}\text { Black } \\
\text { Fraction }\end{array}$ \\
\hline 1 & $96-100$ & 12.9 & 2.3 \\
\hline 2 & $90-96$ & 12.9 & 2.6 \\
\hline 3 & $86-90$ & 12.8 & 3.5 \\
\hline 4 & $82-86$ & 12.0 & 6.8 \\
\hline 5 & $78-82$ & 10.2 & 13.3 \\
\hline 6 & $73-78$ & 10.6 & 9.1 \\
\hline 7 & $69-73$ & 7.1 & 14.8 \\
\hline 8 & 63-69 & 7.1 & 15.9 \\
\hline 9 & $56-63$ & 8.2 & 11.2 \\
\hline 10 & $29-56$ & 6.2 & 20.6 \\
\hline $\mathrm{N}$ & & 2,774 & 725 \\
\hline
\end{tabular}

\begin{tabular}{|c|c|c|}
\hline \multicolumn{3}{|c|}{ May 1970 Examination } \\
\hline $\begin{array}{l}\text { Score } \\
\text { Range }\end{array}$ & $\begin{array}{l}\text { White } \\
\text { Fraction }\end{array}$ & $\begin{array}{c}\text { Black } \\
\text { Fraction }\end{array}$ \\
\hline $94-100$ & 12.7 & 2.9 \\
\hline $92-94$ & 12.1 & 4.0 \\
\hline 89-92 & 11.8 & 5.5 \\
\hline $87-89$ & 12.2 & 4.2 \\
\hline $84-87$ & 10.8 & 8.0 \\
\hline $80-84$ & 10.5 & 9.3 \\
\hline $76-80$ & 9.8 & 10.4 \\
\hline $70-76$ & 8.6 & 13.8 \\
\hline $61-70$ & 7.1 & 17.9 \\
\hline $0-61$ & 4.5 & 24.2 \\
\hline & 4,511 & 1,002 \\
\hline
\end{tabular}

\begin{tabular}{|c|c|c|c|c|c|c|}
\hline \multirow[b]{2}{*}{ Decile } & \multicolumn{3}{|c|}{ June 1979 Examination $^{1}$} & \multicolumn{3}{|c|}{ Pooled 1998-1999 Examinations ${ }^{1}$} \\
\hline & $\begin{array}{l}\text { Score } \\
\text { Range }\end{array}$ & $\begin{array}{c}\text { White } \\
\text { Fraction }\end{array}$ & $\begin{array}{c}\text { Black } \\
\text { Fraction }^{2} \\
\end{array}$ & $\begin{array}{l}\text { Score } \\
\text { Range }\end{array}$ & $\begin{array}{c}\text { White } \\
\text { Fraction }\end{array}$ & $\begin{array}{c}\text { Black } \\
\text { Fraction }^{2}\end{array}$ \\
\hline 1 & $99-110$ & 10.0 & 3.9 & $75-85$ & 16.2 & 4.1 \\
\hline 2 & $97-98$ & 15.4 & 5.1 & $72-74$ & 13.5 & 5.3 \\
\hline 3 & $95-96$ & 15.4 & 8.3 & $69-71$ & 14.8 & 8.0 \\
\hline 4 & $93-94$ & 13.1 & 9.4 & $66-68$ & 13.8 & 9.2 \\
\hline 5 & $91-92$ & 11.4 & 10.4 & $63-65$ & 11.4 & 10.7 \\
\hline 6 & $89-90$ & 8.8 & 10.9 & $60-62$ & 9.1 & 11.2 \\
\hline 7 & $86-88$ & 9.1 & 14.1 & $56-59$ & 8.5 & 14.6 \\
\hline 8 & $81-85$ & 9.3 & 17.9 & $51-55$ & 6.8 & 15.3 \\
\hline 9 & $71-80$ & 7.1 & 18.9 & $41-50$ & 4.7 & 15.9 \\
\hline 10 & $0-70$ & NA & NA & $0-40$ & 1.2 & 5.6 \\
\hline $\mathrm{N}$ & & 19,109 & 9,858 & & 13,009 & 11,197 \\
\hline
\end{tabular}

Notes: ${ }^{1}$ Because of test score aggregation, score ranges are approximate deciles. ${ }^{2}$ Black includes African Americans and Latinos. For the 1968 and 1970 examinations, the distribution of scores is available separately for African Americans and Latinos. The distributions for these two groups are quite similar. 